Discussion

Papers

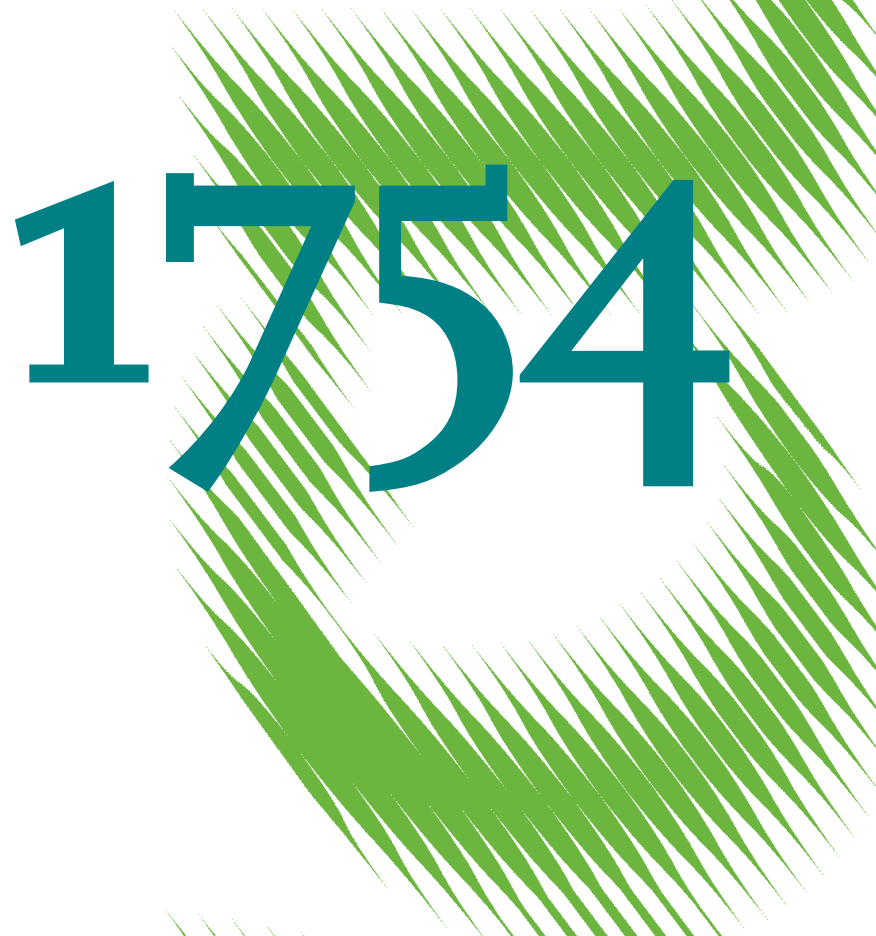

Macroeconomic Effects of Government Spending: the Great Recession was (really) different 
Opinions expressed in this paper are those of the author(s) and do not necessarily reflect views of the institute.

IMPRESSUM

(C) DIW Berlin, 2018

DIW Berlin

German Institute for Economic Research

Mohrenstr. 58

10117 Berlin

Tel. +49 (30) $89789-0$

Fax +49 (30) $89789-200$

http://www.diw.de

ISSN electronic edition 1619-4535

Papers can be downloaded free of charge from the DIW Berlin website:

http://www.diw.de/discussionpapers

Discussion Papers of DIW Berlin are indexed in RePEc and SSRN:

http://ideas.repec.org/s/diw/diwwpp.html

http://www.ssrn.com/link/DIW-Berlin-German-Inst-Econ-Res.html 


\title{
Macroeconomic effects of government spending: the Great Recession was (really) different ${ }^{1}$
}

\author{
Mathias Klein \\ DIW Berlin ${ }^{2}$ \\ Ludger Linnemann ${ }^{3}$ \\ TU Dortmund University
}

August 15, 2018

\begin{abstract}
We estimate the effect of government spending shocks on the US economy with a time-varying parameter vector autoregression. The recent Great Recession period appears to be characterized by uniquely large impulse responses of output to fiscal shocks. Moreover, the particularity of this period is underlined by highly unusual responses of several other variables. The pattern of fiscal shock responses neither completely fits the predictions of the New Keynesian model of an economy subject to the zero lower bound on nominal interest rates, nor does it suggest regular variation of fiscal policy effects depending on the state of the business cycle. Rather, the Great Recession period seems special in that government spending shocks had a strongly negative effect on the spread between corporate and government bond yields and a strongly positive effect on consumer confidence and private consumption spending.
\end{abstract}

JEL: E32, E62

Keywords: Fiscal policy, government spending, vector autoregression, time-varying parameters

\footnotetext{
${ }^{1}$ We thank Kenneth D. West and two anonymous referees for helpful comments and suggestions.

${ }^{2}$ DIW Berlin, D-10117 Berlin, Germany, phone: +49 (0)30 89789 483, email: mklein@diw.de.

${ }^{3}$ TU Dortmund University, Department of Economics, D-44227 Dortmund, Germany, phone: +49 (0)231 755 3102, email: ludger.linnemann@tu-dortmund.de.
} 


\section{Introduction}

The recent literature has produced a large number of papers that estimate the effects of government spending on macroeconomic activity. Interest in this topic is driven in large part by the question whether fiscal stimulus measures are able to lift the economy out of a recession. The debate has become particularly important in the aftermath of the recent Great Recession following the financial crisis, where monetary policy had lost its conventional means of influencing the economy through interest rate decreases and the US government enacted the Recovery and Reinvestment Act in 2009 intended as a countercyclical fiscal measure. Empirical estimates using linear constant-parameter models with aggregate data tend to find moderate effects of fiscal spending shocks on output. However, a still unresolved question is whether fiscal policy has indeed the same macroeconomic effects under all conditions and in all time periods, as presumed in most empirical models, or if there are important nonlinear or time-varying effects of fiscal policy shocks. In particular, a number of papers have found time-varying government spending multipliers on output (e.g. Bilbiie et al., 2008, Auerbach and Gorodnichenko, 2012, Blanchard and Leigh, 2013), whereas others find little evidence against constant (linear) multipliers (e.g. Owyang et al., 2013, Ramey and Zubairy, 2017).

Motivated by this controversy in the literature, in this paper we explore time variation in the effect of government spending shocks on the US economy by means of time-varying parameter vector autoregressions. Time-varying parameter VARs have relatively often been used in studies focusing on monetary policy (e.g. Primiceri, 2005), but have gained comparatively little attention in the fiscal policy area. In particular, we employ the kernel weighted time-varying parameter model of Giraitis et al. (2014, 2015). This method allows to detect general patterns of time variation in impulse responses to government spending while, due to its non-parametric approach, imposing relatively few structural assumptions concerning the temporal evolution of the parameters. Importantly, the kernel based estimation method allows us to include a relatively large number of variables in a computationally straightforward way to shed light on specific aspects of the fiscal transmission process and possible changes thereof.

Our main result is twofold: first, while there is some time variation in the economy's response to government spending shocks in several periods, by far the largest change occurs in the period surrounding the Great Recession. The impulse response of real GDP averaged over eight quarters following a fiscal shock is roughly three times as large in this period as would be estimated by the corresponding constant parameter VAR using the same set of variables. Second, the change in the output effects of fiscal policy is accompanied by large changes in the impulse responses of several other variables that are also specific to this episode. In particular, we observe a strong negative effect of government shocks on the spread between corporate bond yields and long-term government bond yields, and a strong positive effect on a survey-based measure of consumer confidence and on private 
consumption.

Since the estimated changes in fiscal policy effects during the Great Recession and its aftermath are economically large and statistically significant, the question arises what makes this period special in this respect. While we do not propose a specific theoretical model, several insights can be gained from our relatively agnostic time-varying VAR results. In particular, one of the leading theories to explain why government spending effects may be higher at some times than at others is the New Keynesian model that implies potentially very large fiscal policy effects when the zero lower bound on nominal interest rates is binding (Christiano et al., 2011). In this model, higher government spending raises expected inflation and thus, with nominal interest rates stuck at zero, lowers the real interest rate and hence stimulates private spending.

While we do find some positive effects of government spending both on realized and survey-measured expected inflation during the Great Recession, there is no evidence of a negative response of real interest rates. This is true both if we measure nominal interest rates by the $\mathrm{Wu}$ and Xia (2016) shadow interest rate that we include as a control variable to capture unconventional monetary policy measures enacted in the relevant period (in order to safeguard against confounding monetary policy effects with temporally coincident fiscal actions), or if we look at the real rate response based on government-related interest rates like public bond yields. Rather, as the strongly negative effect of fiscal shocks on the corporate-to-government bond yield spread that occurs in the Great Recession suggests, the relevant transmission mechanism in this period seems to have involved a mitigating effect of fiscal intervention on the financing costs of firms, possibly due to reduced private sector default risk. Such an interpretation is consistent with the financial accelerator mechanism of fiscal policy that has theoretically been studied by Canzoneri et al. (2016).

If the interpretation that government spending changes have helped to alleviate the consequences of financial frictions in the Great Recession is correct, one would expect that they also had a positive partial effect on private investment spending. While we do find comparatively large positive responses of investment, the statistical uncertainty is rather large in this respect, which prevents very sharp conclusions. However, there is another mechanism that seems to have played a sizeable role, namely a markedly positive effect on survey-measured consumer confidence, associated with a strongly positive response of private consumption to fiscal spending shocks. As argued by several authors, fiscal interventions might improve sentiment if they show policy-makers' commitment to macroeconomic stabilization, a situation that was arguably present during the Great Recession. This, in turn, would stimulate economic activity because active fiscal policy preserved the economy from an even larger contraction. The confidence channel of fiscal policy has recently been empirically explored by Bachmann and Sims (2012) and Beetsma et al. (2015), and a theoretical model highlighting this channel has been proposed by Guimaraes et al. (2016). More generally, Barsky and Sims (2012) show that confidence 
innovations are associated with sizeable consumption and income growth. Our evidence suggests the confidence channel may have been an important driver of the large output effects to government spending shocks during the Great Recession period.

Much of the recent debate on non-constant effects of fiscal policy has been centered about the question whether fiscal shock effects are state-dependent, in the sense of being systematically different over the state of the business cycle. Auerbach and Gorodnichenko (2012) find that government spending shocks are larger in recessions than in booms by using smooth transition vector autoregressions. Ramey and Zubairy (2017) use local projections and find limited evidence for a dependence of fiscal shock effects on the state of the business cycle, though their estimated multipliers tend to be higher in low interest rate periods suggesting a possible role of the zero bound on nominal interest rates. Thus, the evidence on state-dependence in the response of macroeconomic variables to fiscal policy appears to be inconclusive. In contrast to these approaches, the time variation in our kernel-based variable parameter VAR is not constrained to depend on the state of the business cycle. Given the conflicting results in the previous literature, we view this less structured approach as an advantage. As is well known from theory, the size of the effect of a fiscal spending shock on the economy should be expected to depend on a large number of circumstances, like for example the monetary policy stance, the extent of financial constraints on households, the international environment, or the way additional spending is financed. Since there is no compelling reason to expect that all of these conditions are perfectly aligned with a binary definition of the state of the business cycle, our approach allows for an unrestricted estimation of time-varying policy effects. However, there is the usual trade-off that while less structured estimation procedures reduce the risk of bias through incorrect restrictions, they are also less efficient than estimators that impose the correct structure such that the former may suffer from larger statistical uncertainty of the results. We view this trade-off as favoring our more agnostic and exploratory rather than confirmatory approach in consideration of the inconclusive state of the debate in the literature.

Overall, we find relatively little evidence that the effectiveness of fiscal policy is systematically amplified during episodes of high economic slack. When restricting our sample to the period before the Great Recession, output responses to government spending shocks are on average hardly larger in recessions than they are in booms. This result is robust to different ways of defining recessionary periods. In any case, however, our estimates suggest that the Great Recession stands out as a very special episode in which fiscal interventions had unusually strong effects that were much larger than in any other recession in the sample period.

The rest of the paper is structured as follows. Section 2 describes the econometric method and our preferred baseline specification. In Section 3, we present our baseline estimates, more specifically time-varying output responses to government spending shocks. 
Moreover, we assess the robustness of our results. Section 4 explores the underlying transmission mechanism that could potentially explain the results. In particular, we present evidence indicating that our findings cannot be explained by a significant reduction of the real interest rate as favored by the standard New Keynesian model. In addition, we highlight the importance of fiscal transmission via interest spreads and consumer confidence, and investigate whether our estimates are better explained by time or state dependence. Finally, Section 5 concludes.

\section{Econometric model}

\subsection{Method}

The nonparametric time-varying VAR model that we use is due to Giraitis et al (2014, $2015)$. Let $x_{t}$ be an $(n \times 1)$ vector of observations on $n$ variables observed at $t=1, \ldots, T$. The reduced form of the time-varying VAR to be estimated is

$$
x_{t}=a_{t}+A_{1 t} x_{t-1}+\ldots+A_{p t} x_{t-p}+u_{t}
$$

where $a_{t}$ is an $(n \times 1)$ vector of time-varying intercepts, and the $A_{i t}$ are the $(n \times n)$ coefficient matrices for the $i=1, \ldots, p$ lagged variables, whereas $u_{t}$ is a vector of serially uncorrelated reduced form disturbances with contemporaneous covariance matrix $\Sigma_{t}$. In more compact form, letting $z_{t-1}=\left(1, x_{t-1}^{\prime}, \ldots, x_{t-p}^{\prime}\right)^{\prime}$ and $A_{t}=\left[a_{t}, A_{1 t}, \ldots, A_{p t}\right]$, the model is

$$
x_{t}=A_{t} z_{t-1}+u_{t},
$$

and we assume that $p$ pre-sample observations are available. The kernel-weighted least squares estimator $\widehat{A}_{t}$ of the reduced from parameter matrices is then obtained as

$$
\widehat{A}_{t}=\left(\sum_{j=1}^{T} k_{t j} x_{j} z_{j-1}^{\prime}\right)\left(\sum_{j=1}^{T} k_{t j} z_{j-1} z_{j-1}^{\prime}\right)^{-1},
$$

where the kernel function $k_{t j}$ is taken to be the Gaussian kernel $k_{t j}=\frac{1}{\sqrt{2 \pi}} \exp \left\{-0.5\left(\frac{t-j}{h}\right)^{2}\right\}$, and $h$ is a bandwidth parameter. Following Giraitis et al. (2014), we set the bandwidth to $h=\sqrt{T}$ throughout, where we use the longest available sample size and keep $h$ fixed when changing model specifications.

The resulting residuals $\widehat{u}_{t}$ are then used to estimate the time-varying covariance matrix $\Sigma_{t}$ according to

$$
\widehat{\Sigma}_{t}=\left(\sum_{j=1}^{T} k_{t j}\right)^{-1}\left(\sum_{j=1}^{T} k_{t j} \widehat{u}_{j} \widehat{u}_{j}^{\prime}\right) .
$$

To allow for a structural interpretation of VAR disturbances as economic shocks, the reduced form disturbances need to be orthogonalized. Throughout, we use a Cholesky decomposition to orthogonalize $\widehat{\Sigma}_{t}$, and discuss the usual implication of contemporaneous recursiveness of the structural shocks thus obtained in section 3 below in the context of 
robustness exercises. Based on $\widehat{A}_{t}$ and the Cholesky decomposition of $\widehat{\Sigma}_{t}$, we compute time-varying impulse responses. We will discuss the identification issues associated with this approach in the following section.

The method amounts to computing a standard VAR for each sample time point $t$ with data weighted by a bell-shaped Gaussian kernel. Thus, while all data are used at each point, greater importance is given to the data at and near the sample point considered. These properties make the nonparametric time-varying parameter VAR particularly suited for our purposes. In particular, the method has some advantages relatively to leading alternatives used in the macroeconomic literature. In comparison to the parametric timevarying VAR models that have often been used in macroeconomics (e.g. Primiceri, 2005) which assume that the individual parameters follow random walks, the computional burden associated with the method by Giraitis et al. $(2014,2015)$ is much lower. This allows us to use a relatively large model that offers the potential to explore the transmission mechanism of government spending shocks in considerable detail, while keeping the computational complexity limited since the estimator is a least squares variant.

The other two main alternatives to our approach are the smooth transition VAR model by Auerbach and Gorodnichenko (2012) and the local projection method as proposed by Jordá (2005) and applied, among others, by Owyang et al. (2013) and Ramey and Zubairy (2017). Within both models, the parameters are allowed to vary across different states of the economy, for example across booms and recessions. Importantly, for both empirical models, an indicator variable that captures the state of the economy has to be defined before the estimation. However, neither is there a clear consensus in the literature what particular state of the economy is most important for the effects of government spending shocks, nor is there a unique way to define different states. While some authors find that fiscal multipliers vary considerably between booms and recessions (e.g. Auerbach and Gorodnichenko, 2012), other studies find that the conduct of monetary policy (ZLB versus normal times) is of major importance when studying state-dependent fiscal multipliers, whereas the state of the business cycle only plays a minor role (Miyamoto et al., 2017 and Ramey and Zubairy, 2017). Furthermore, economic expansions and recessions can be defined through different and sometimes mutually contradictory measures, e.g. through official recession dates, an output gap measure, or a threshold for the unemployment rate. Moreover, there exists a competing view suggesting that rather than the state of the business cycle it is the particular regime of fiscal-monetary policy interactions (e.g. Davig and Leeper, 2011; Leeper et al., 2017) that is the relevant condition for temporal change in policy effects. The method we use bypasses this issue by assuming that the parameters are time-dependent in an unconstrained fashion and not (necessarily) state-dependent. The advantage is that there is no need to specify an indicator to define the possible states before estimation. The time-dependent model thus imposes less structure, since the pattern of time variation in the parameters is not a priori restricted to fit to a particular definition 
of states. If the true data generating process features state dependence, on the other hand, this should be detected by the unconstrained time-varying parameter model that we use as well, whereas if the time variation does not fit to a state-dependent pattern, the nonparametric method avoids misspecification bias.

However, there obviously is the usual trade-off between empirical methods that impose a more or less tightly specified structure: while tighter specifications risk bias if the specification is wrong, they also improve efficiency if they are correct. The relatively unstructured nonparametric model that we use is thus most useful for a more explorative analysis in cases where little is known about the appropriate pattern of time variation. Arguably, the analysis of fiscal policy can be seen as a case in point, as witnessed by the inconclusive and partly contradictory results in the previous literature.

\subsection{Specification}

We use quarterly US macroeconomic data for a sample ranging from 1960Q1 to 2015Q4. Our baseline model specifies the vector $x_{t}$ to consist of $x_{t}=\left(g_{t}, y_{t}, \tau_{t}, d_{t}, \pi_{t}, r_{t}, s_{t}, c c_{t}\right)^{\prime}$. Here $g_{t}$ is the growth rate of real government spending, $y_{t}$ is the growth rate of real GDP, $\tau_{t}$ is taxes as a fraction of GDP, $d_{t}$ is the change in the ratio of government debt over GDP, $\pi_{t}$ is inflation measured as the growth rate of the GDP deflator, $r_{t}$ is the Wu and Xia (2016) shadow nominal federal funds rate, $s_{t}$ is the spread between BAA rated corporate bond yields and 10 year government bond yields, and $c c_{t}$ is an index of consumer confidence. Details on data sources are given in the online Appendix. Throughout, we use a specification with four lags and a constant, and choose the bandwidth for the kernel weighting function as the square root of the sample size, as suggested by Giraitis et al. (2014).

Variables are chosen to control for the financing side of the government budget (through taxes and debt) and for monetary policy (through inflation and a short nominal interest rate), as well as with the intention of uncovering the time-varying patterns of the fiscal transmission mechanism. For the latter purpose, as argued below, the spread and consumer confidence turn out important. As these two variables are the only somewhat unusual choices, we below ascertain that our results concerning the effect of fiscal policy on the other variables are robust to leaving them out.

Several studies show that the conduct of monetary policy influences the macroeconomic effects of fiscal policy (e.g. Canova and Pappa, 2011; Davig and Leeper, 2011). Specifically, the extent to which monetary policy reacts to the consequences of fiscal spending shocks is an important determinant of their size. Therefore, in any study of the effects of government spending shocks it is important to explicitly control for the stance of monetary policy. Usually, this can be done by including a short-run interest rate as the monetary instrument and the inflation rate as the target of monetary policy in the variable vector. However, our sample includes the period of the zero lower bound (ZLB) in which the Federal Funds 
Rate rate was essentially stuck at zero. In this period, the Federal Funds Rate thus arguable does not capture the monetary policy stance to the extent that monetary policy has switched to using unconventional measures like quantitative easing. In other words, if unconventional monetary policy succeeded at boosting the economy during the ZLB episode, there is a risk that this effect is wrongly ascribed to other shocks, e.g. fiscal shocks, if there is no control variable for the unconventional monetary policy in the model. To capture the monetary policy stance, thus, we include the shadow nominal interest rate that was constructed by $\mathrm{Wu}$ and Xia (2016). Before 2009, the ZLB was not binding, and thus the shadow rate equalled the Federal Funds Rate. However, the two rates differ thereafter, a period in which the Federal Reserve has undertaken different unconventional monetary policy actions that do not map into movements in the Federal Funds Rate, but which are reflected in Wu and Xia's (2016) shadow rate. In particular, the shadow rate has become negative during the ZLB signalling the expansionary monetary policy stance in this period.

To sum up, controlling for unconventional monetary policy through the shadow rate is important since we wish to maintain a conservative baseline, since to the extent that unconventional monetary measures have indeed been stimulative, this variable protects us from misinterpreting the success of monetary policy through quantitative easing or forward guidance as the result of fiscal policy decisions that took place in the same time frame. That said, all results are very similar when we use the Federal Funds Rate instead of the shadow rate. Also, much the same results (for a slightly shorter sample) emerge if we follow an argument by Gertler and Karadi (2015) and use the two year treasury rate to capture the effect of unconventional monetary policy which is supposed to work through longer term interest rates. The shadow rate is available from 1960q1 onwards, which we use as our sample starting point. Additionally, all results are robust to extending the sample to start in 1949q1 by using the short T-Bill rate for the pre-1960 part of the sample.

The inclusion of the spread variable $s_{t}$ that measures the yield difference between BAA rated private bonds and long-term government bonds intends to capture the role of financial frictions. Many recent papers argue that financial frictions are important for understanding the macroeconomic consequences of economic shocks. Gertler and Karadi (2015) find that the monetary policy transmission mechanism crucially depends on how credit costs react to the policy intervention. Concerning the interrelation between fiscal policy and credit market imperfections, Fernández-Villaverde (2010) and Canzoneri et al. (2016) demonstrate in theoretical models that financial frictions should affect the size of the government spending multiplier. To account for the possibly important role of financial frictions in the transmission mechanism of fiscal policy, we include the spread variable $s_{t}$ in the vector of control variables. The idea is that a worsening of financial frictions should be reflected in an increase of the private bond interest rate as compared to a long-term 
government bond rate, since the former as opposed to the latter incorporates the perceived risk of default on the part of private debtors. We will argue below in section 4 that this variable appears to play a crucial role in the time-varying transmission process of fiscal policy.

Finally, the inclusion of an indicator of consumer confidence, $c c_{t}$, follows the argument by Bachmann and Sims (2012), who find that confidence is an important determinant of the way in which fiscal policy innovations affect aggregate economic activity. Moreover, also Guimaraes et al. (2016) and Beetsma et al. (2015) argue in favor of the existence of a separate 'confidence channel' of fiscal policy. We will discuss the potential role of this channel in affecting the response of private consumption to government spending shocks below in section 4 .

Our baseline specification recovers the structural government spending shock through a recursive orthogonalization of the reduced form VAR residuals. As is well known, with government spending growth ordered first, this procedure amounts to assuming that government spending reacts to other shocks with at least a one quarter lag, as in Blanchard and Perotti (2002). This assumption relies on the idea that policy makers need time to decide on, approve, and implement changes in fiscal policy. Recent studies by Auerbach and Gorodnichenko (2012), Ilzetzki et al. (2013), and others have used this identification assumption. However, several authors have suggested that this specification is not able to identify structural fiscal shocks if government spending increases are anticipated by private agents, since the economy would react at the time of anticipation possibly well before any observable change in spending (Ramey, 2011). Therefore, below we will explore the robustness of our results by additionally taking up two widely used measures of anticipated government spending.

\section{Time-varying output effects of fiscal policy}

In this section, we show our main result concerning the temporal evolution of the estimated effects of government spending on real output, and assess the robustness of the results.

\subsection{Main result}

We present the time-varying impulse responses to a one percentage point shock to government spending growth. For better readability, the impulse responses pertaining to variables entered in growth rates are converted to log-levels in the impulse response figures throughout the paper. To summarize the considerable time variation in the impulse responses in an easily readable way, we will henceforth concentrate on two summary statistics, namely the size of impulse responses in the impact period, and the average impulse responses over an horizon of 8 quarters following a shock (the full set of responses is given in the online Appendix).

Figure 1 shows the impact and average impulse response of output (converted to loglevels) to a one percent shock to government spending, together with bootstrapped $68 \%$ 
Figure 1: impact and average output responses.
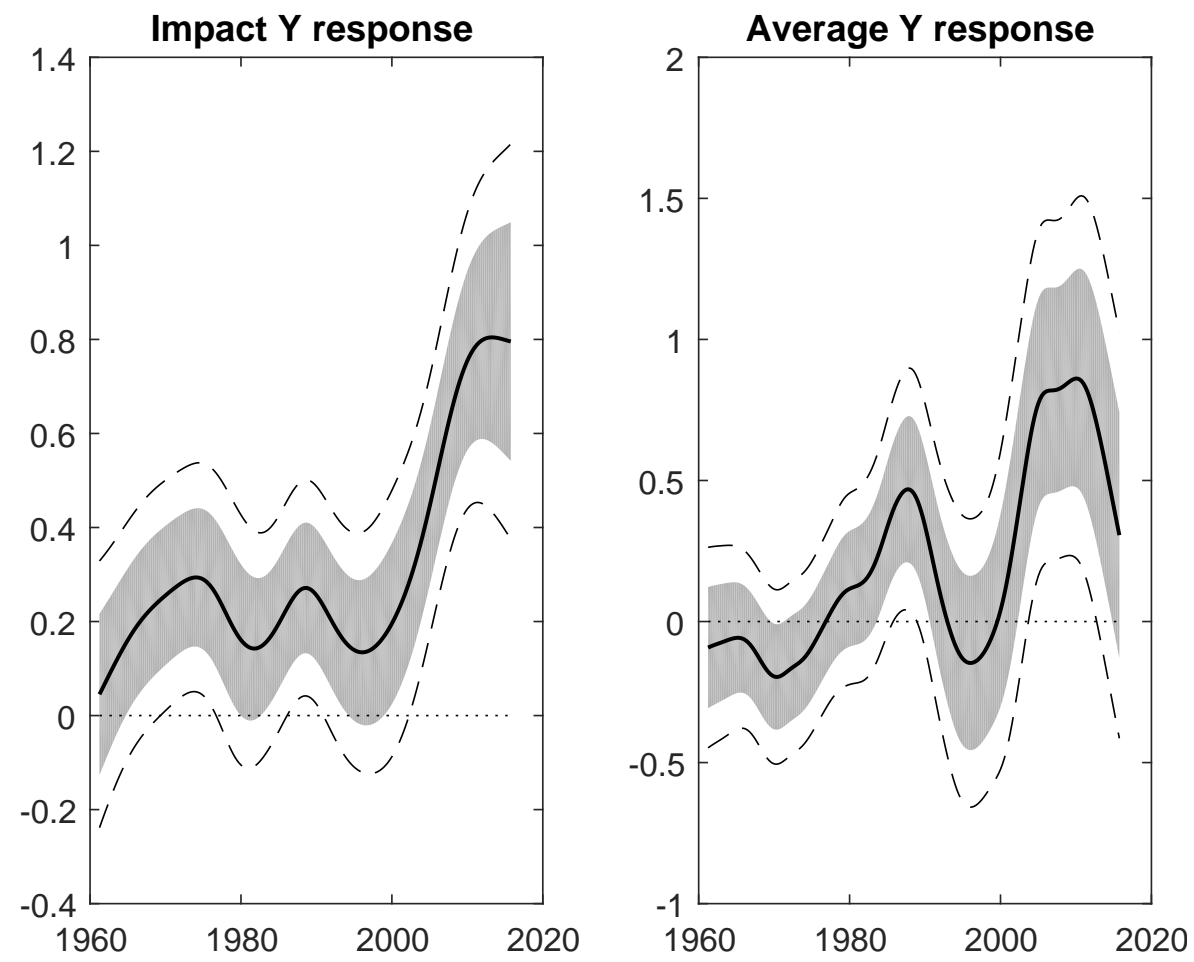

Notes: Solid lines show mean responses. Shaded areas and dashed lines indicate $68 \%$ and $90 \%$ bootstrapped confidence intervals.

and $90 \%$ confidence intervals. The figure summarizes one of our central points: while there is non-negligible time variation in both the impact and average output response, the most conspicuous episode is the time around the Great Recession (GR henceforth) following the financial crisis in 2008. The impact response of output varies around 0.2 for most of the sample, and increases to almost four times that value towards the end of the time period considered. The average eight-quarter impulse responses convey a more general summary of the dynamics of output following a fiscal shock. In many parts of the sample, the average output response is small or even negative. There is some indication of a larger average response in the late 1980ies, and the response is also statistically significantly different from zero during that period. ${ }^{4}$ However, the period surrounding the GR stands out. The average output response is much larger compared to previous episodes and also highly statistically significant. Thus, the effects of government spending shocks appear to have been much stronger in the GR episode.

To put this results into perspective, the American Recovery and Reinvestment Act that was enacted in 2009 mostly focused on tax cuts and extending unemployment insurance. However, the package also included a marked increase in government expenditures and gross investment (which we use as the government spending series) that amounted to 60 Billion US dollar. ${ }^{5}$ This corresponds to a $2 \%$ increase relative to government spending in

\footnotetext{
${ }^{4}$ In section 4, we will relate the larger effect of fiscal policy during the late 1980ies to the positive responses of consumer confidence and private investment to a government spending shock during that episode.

${ }^{5}$ See https://www.bea.gov/recovery/index.htm for further details.
} 
Figure 2: average output and government spending responses.

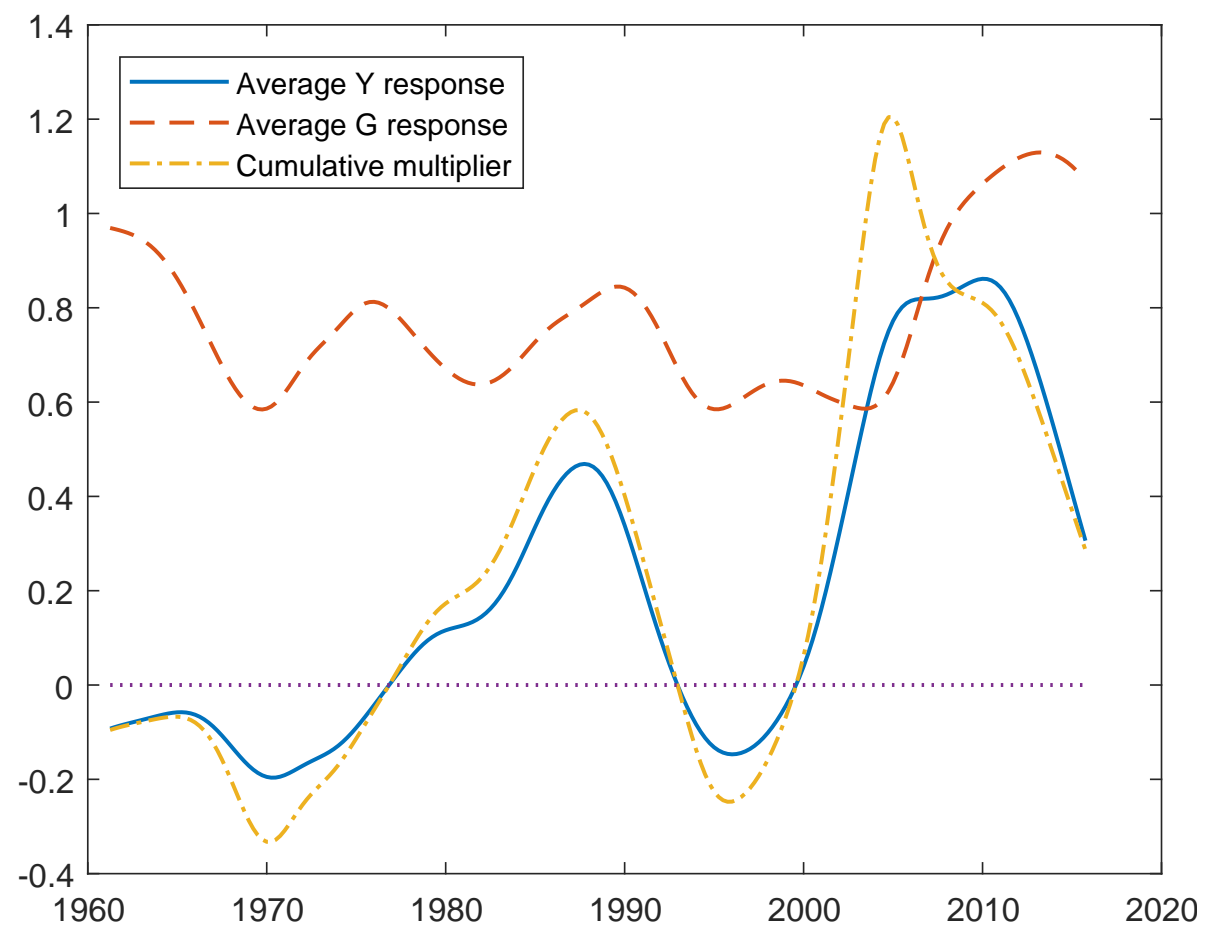

the first quarter of 2009. Thus, although we just capture a fraction of the large-scale fiscal stimulus program in our specific government spending variable, our results are consistent with the view that the American Recovery and Reinvestment Act had a powerful influence on output. ${ }^{6}$

In principle, it might be the case that output appears to react more strongly in the GR episode simply because government spending shocks were more persistent then, such that larger output reactions could be due to a larger size of the cumulative change in government spending. To assess this possibility, Figure 2 shows the average output response together with the average response of government spending itself.

As can be seen from Figure 2, the time variation in the average output response (the solid line) is much larger than the time variation in the average own response of government spending (the dashed line). While there is some indication of a larger average government spending change towards the more recent period, this is not enough to explain the larger size of the average output response. This can also be seen from comparing with a measure of a cumulative government spending multiplier, which is shown in Figure 2 as the dash-dotted line which depicts $\sum_{i=1}^{8} \widehat{y}_{t+i} / \sum_{i=1}^{8} \widehat{g}_{t+i}$, where the hatted variables denote the responses of the log-levels of output and government spending (this cumulative multiplier is also used in Auerbach and Gorodnichenko, 2012, and Ramey and Zubairy, 2017). The cumulative government multiplier tracks the average output response very closely. Therefore, we conclude that differences in the output response do not stem primarily from variations in the size or persistence of government spending changes. Con-

\footnotetext{
${ }^{6}$ For a detailed analysis on the real effects of the American Recovery and Reinvestment Act see, e.g., Chodorow-Reich et al. (2012) or Shoag (2013).
} 
sequently, the substantial time variation in the response of output cannot be explained through differences in the cumulative volume of government interventions. Furthermore, the results change relatively little and the time pattern of the most important changes in the responses remains comparable when we leave out the spread and consumer confidence series, or when we express spending and output in per-capita terms (see the online Appendix).

Are these results the figment of a specification error because government spending changes are anticipated by the private sector, such that the timing of fiscal shocks is incorrectly assessed by the econometric model? To assess this, we compare the baseline results with two alternative specifications which explicitly take into account the fiscal foresight problem. The first uses the variable vector $x_{t}^{1}=\left(\text { news } s_{t}, x_{t}\right)^{\prime}$, where news $s_{t}$ is the fiscal news variable constructed by Ramey and Zubairy (2017), and the second uses $x_{t}^{2}=\left(g f_{t}, x_{t}\right)^{\prime}$, where $g f_{t}$ measures real-time profession forecasts for government spending. news $s_{t}$ is a measure of anticipated government spending equal to the present discounted value of expected future spending as recovered from newspaper sources. $g f_{t}$ is a spliced series of government spending forecasts provided by the Greenbook (1966-2004) and the Survey of Professional Forecasters (1982-2015). We extend the series provided by Auerbach and Gorodnichenko (2012) which covers the period 1966-2008 to include the GR and the following years. Because the forecast variable limits the usable sample, the following estimation results are restricted to the period 1966q3-2015q4. For both specifications, the unanticipated government spending shock is identified as the innovation to $g_{t}$ ordered second (i.e. after newst or $g f_{t}$ ). The change in government spending orthogonal to the respective expectation variable is an unanticipated shock to government spending, in the sense that it was not foreseen by the media or professional forecasters.

Figure 3 shows the impact and average responses of output to a government spending shock under the baseline specification (solid lines, unchanged from above) and the two alternative specifications that control for anticipations of future government spending changes (dotted and dash-dotted lines, respectively). There are some differences in the time pattern of output responses across the three models. Using the government spending forecast variable leads to a slightly larger increase in the impact output response towards the sample end, while it suggests less variation in the average response before 2000. Conversely, with the news variable there appears to be more pronounced variation in the impact responses, with particularly higher reactions than in the other two models in the 1970ies. The average output response in the model with the news variable ordered first tracks the baseline specification for most of the sample quite closely, with the increase in the average response in the more recent sample period slightly delayed. However, the differences between the specifications do not seem to be statistically strong, as both impact and average responses almost entirely fall within the $90 \%$ confidence bands of the baseline model, which are displayed as dashed lines in Figure 3. We conclude that the 
Figure 3: robustness to anticipation.
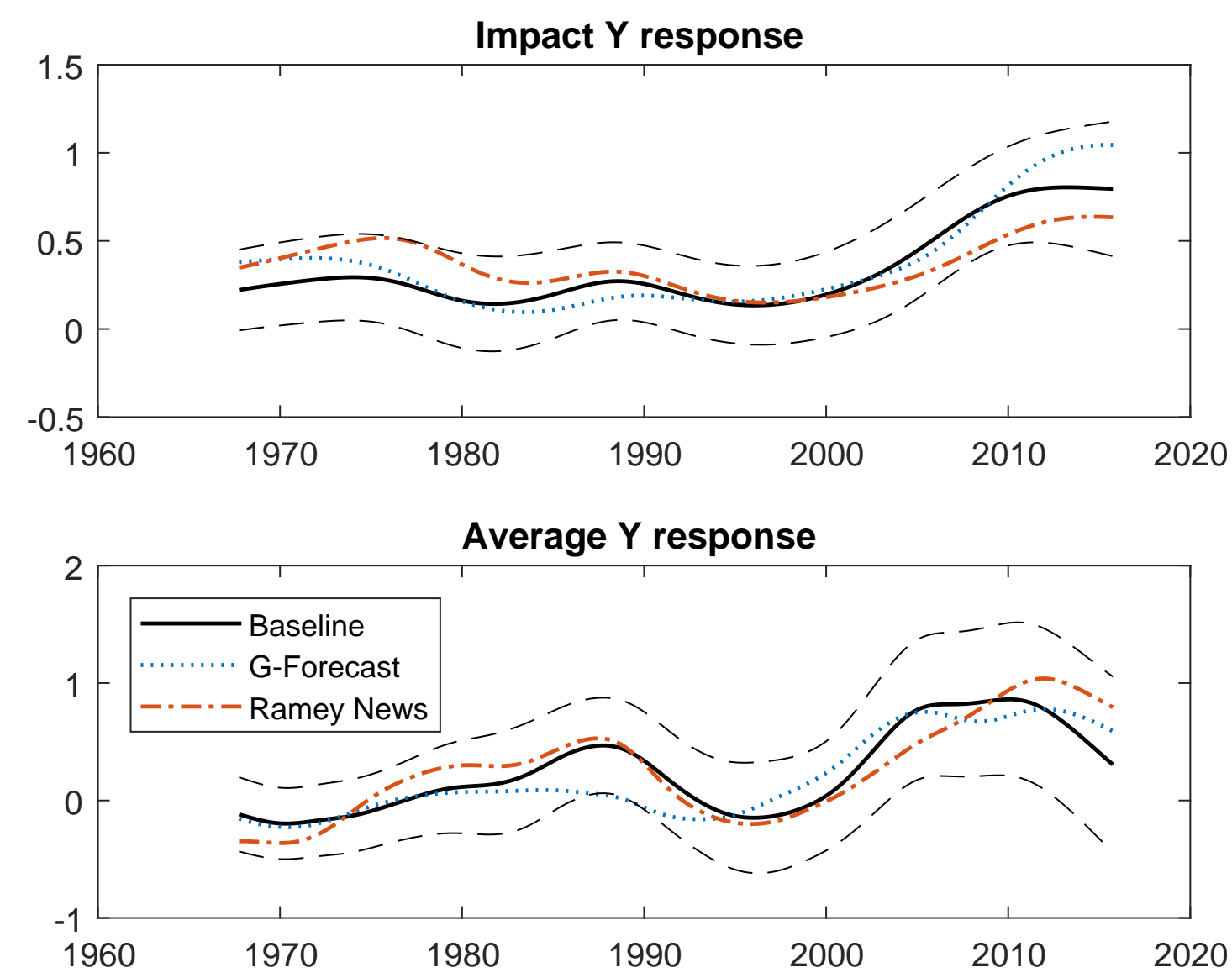

results appear to be robust with respect to controlling for anticipation effects. For the rest of the paper, we therefore work with the simpler baseline specification with government spending ordered first (we have checked that all conclusions would remain the same for the other specifications as well).

\subsection{Understanding the timing of results}

As can be seen by the results shown in Figure 1, while the largest output responses occur around the height of the GR, both impact and average responses appear to start to rise earlier, around the year 2000. The question thus arises whether these changes are due to unusual properties of the data pertaining to the GR itself or rather to those of the early 2000s. ${ }^{7}$ It is possible, in principle, that our estimation method misses the timing of important parameter changes since it uses a symmetric (Gaussian) kernel that, at each interior sample point, weighs data points both preceding and following the respective date more heavily (the online Appendix depicts the kernel weighting function graphically).

To assess the influence of the GR on the change in output effects, we re-estimate the model recursively with a varying sample end point. Specifically, instead of using all $T$ observations as above, we choose a sample end point $T^{*} \leq T$ and redo the estimation based on data up to and including $T^{*}$, and repeat this for $T^{*}$ varying from $2000 \mathrm{q} 1$ to 2015q4. For each of the samples restricted to end in $T^{*}$, we compute the average eight-

\footnotetext{
${ }^{7}$ Thanks are due to an anonymous referee for pointing out this possibility.
} 
Figure 4: timing of results.
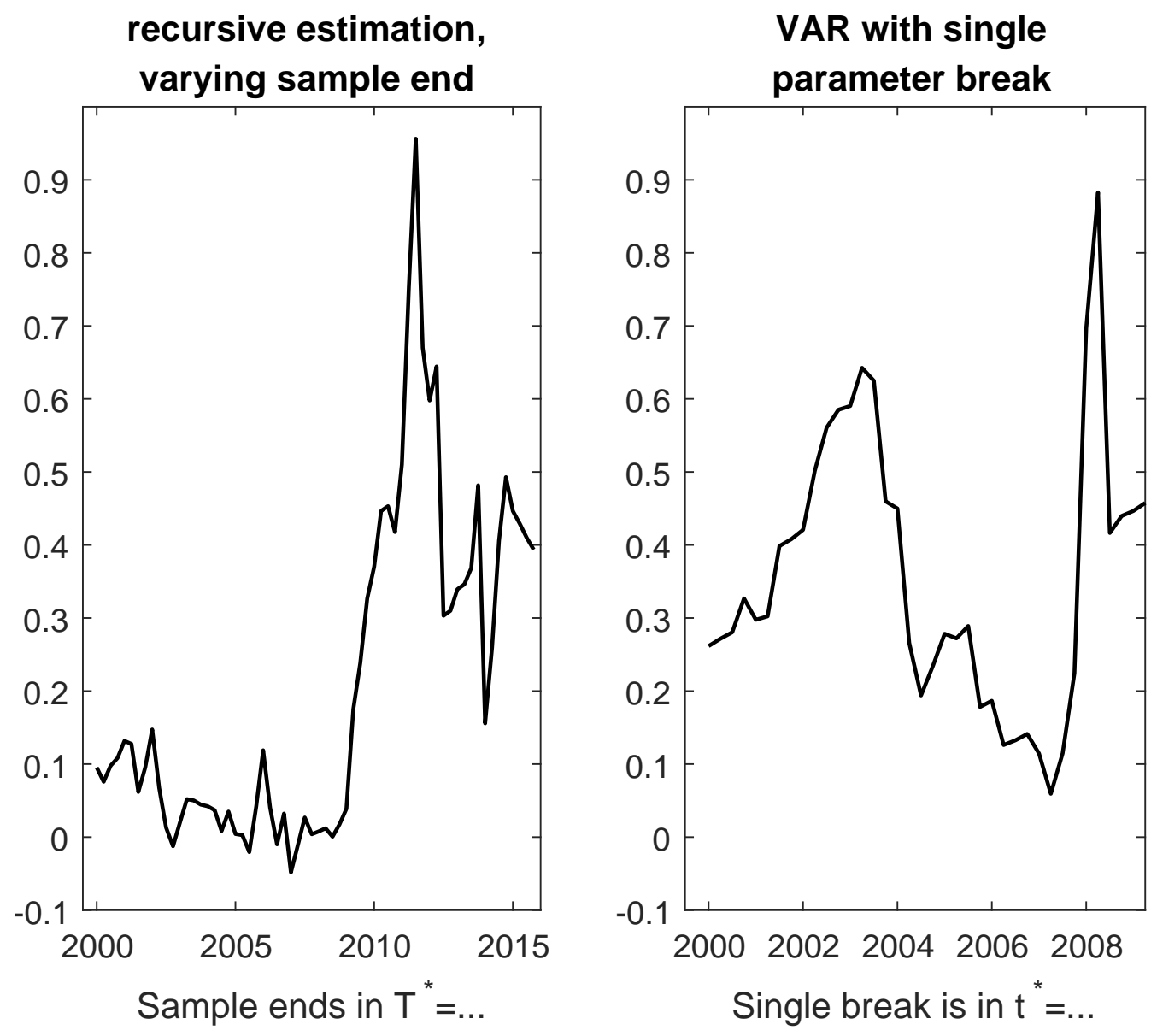

quarter output response at the sample end point $T^{*}$. The left panel of Figure 4 shows the results plotted against $T^{*}$. Through this recursive estimation approach, we effectively exploit that the kernel must become backward-looking at the sample end point and ensure that only the information prior to and including date $T^{*}$ is used. Note that by this procedure we effectively impose a one-sided weighting scheme at $T^{*}$, which is not efficient since it ignores information in the right side of its neighborhood, but which allows to more precisely determine the timing of any abrupt change. To ensure that the number of observations that receive non-negligible weights remains roughly the same, we double the bandwidth for this exercise (the online Appendix shows Monte Carlo results suggesting that this procedure works well to detect the timing of parameter changes).

As the left panel of Figure 4 shows, for samples restricted to end before the GR there is no noteworthy increase in the average output response. The increase appears to start around $T^{*}=2009$, hence as soon as data from the height of the GR enter the sample, and then quickly becomes larger as $T^{*}$ moves forward to include more data from the GR period and its aftermath. Hence, we conclude that indeed the GR data appear to account for the estimated changes, whereas output effects of fiscal shocks in the early 2000s are generally small and show only limited time variation. The same general conclusion arises if we decrease the bandwidth parameter $h$ to increase the relative weight on observations 
close to a particular sample point (see the online Appendix).

To bring the timing of parameter changes out as starkly as possible, we also compare the results with an alternative simpler model where we impose a single once-and-for-all break in all parameters. Specifically, adapting the notation from (2), we estimate

$$
\widetilde{x}_{t}=A_{1} \widetilde{z}_{t-1}+I_{t^{*}} A_{2} \widetilde{z}_{t-1}+u_{t},
$$

where $\widetilde{z}_{t-1}=\left(1, \widetilde{x}_{t-1}^{\prime}, \ldots, \widetilde{x}_{t-4}^{\prime}\right)^{\prime}$, and $I_{t^{*}}=1$ if $t<t^{*}$ and zero otherwise, with $t^{*}$ denoting the sample point where a break in the coefficients is assumed. $A_{1}$ and $A_{2}$ are potentially different parameter matrices. Since this doubles the parameters to be estimated, we need to economize on degrees of freedom and reduce the model to let the vector $\widetilde{x}_{t}$ contain only government spending and output growth, the tax rate, the shadow rate and the bonds rate spread (note that all previous conclusions are also robust to using this smaller data set). The right panel of Figure 4 shows the results for the post-break average output response, where we let the break point $t^{*}$ vary between $2000 \mathrm{q} 1$ and $2009 \mathrm{q} 2$ (the last date that allows to retain enough post-break observations).

As can be seen from the right panel of Figure 4, using this alternative method there is some evidence of higher average output responses for break dates in the early 2000s, but the most notable jump is realized for a break date $t^{*}$ starting between 2007 and 2008, thus coinciding with the onset of the GR. Thus, again it seems that the bulk of the changes that we observe in the later sample parts is due to the data points related to the early GR period, corroborating our conclusion that this episode shows highly unusual fiscal policy effects. ${ }^{8}$

\section{Further Evidence}

In this section, we explore which transmission mechanism could be empirically responsible for the unusually strong output effects of government spending in the period around the GR that we have documented above by discussing the effects on other variables.

\subsection{Transmission Mechanism}

One of the leading theories attempting to explain the extraordinary features of the GR is the New Keynesian view that is theoretically elaborated in Christiano et al. (2011) and Eggertsson (2011). This view attributes the severity of the recession, and the slow recovery in its aftermath, to the zero lower bound (ZLB) on nominal interest rates. Since the Federal Funds Rate quickly dropped to close to zero in the GR, and was stuck at this lower bound afterwards, monetary policy could not sufficiently counteract the recession as it would usually have done by lowering the interest rate further. Consequently, as shown in Christiano et al. (2011) or Eggertsson (2011), with monetary policy impotent

\footnotetext{
${ }^{8}$ In the online Appendix, we show the results of estimating by maximum likelihood a smaller specification under the assumption that the parameters follow random walks with normally distributed innovations. While this yields much less time variation in the responses, most of what variation there is coincides with the GR.
} 
fiscal policy should become particularly powerful. The New Keynesian mechanism is that higher government spending should raise expected inflation, which given constant nominal interest rates at the ZLB translates into a decrease in the real interest rate which would increase aggregate demand and thus output.

In this section, we analyze whether the empirical evidence is in accordance with the New Keynesian view. First, note that in our baseline empirical specification we have included an interest rate that is not bounded by the ZLB. As stated above our preferred measure of a short-run nominal interest rate is not the Federal Funds Rate, which was indeed stuck at approximately zero in the GR, but the Wu and Xia (2016) shadow interest rate, which (being a theoretical construct and not an observed market interest rate) is free to drop below zero (which indeed it did in the GR episode). The idea of using the shadow rate was to capture the effects of monetary stimulus through unconventional measures. However, it is important to notice that our results concerning the effects of fiscal policy are in no way an artefact of using this particular measure for the stance of monetary policy. Indeed, all results are highly similar when the shadow rate is replaced by the observed Federal Funds Rate. Thus, while the shadow rate dropped below zero in the GR, this does certainly not mean that the ZLB was unimportant, since it is possible that considerably more monetary stimulus would have been necessary to prevent the severity of the GR and that in the absence of the ZLB the Federal Funds Rate would have declined more than the shadow rate did.

If the New Keynesian view is correct, fiscal policy was particularly expansionary in the GR since it should have raised expected inflation and thus lowered the real interest rate. Figure 5 shows the average eight-quarter response of realized inflation in the left panel and the one of expected inflation as measured by the Survey of Professional Forecasters in the right panel. The expected inflation series measures the inflation forecast for a given quarter that was conducted in the previous quarter based on all information available up to this point. Since this variable is only available from 1969 onwards, the sample is shortened accordingly. Both estimates in Figure 5 are derived from a model where expected inflation enters as an additional variable.

Figure 5 shows that both realized inflation (left panel) and survey measured expected inflation (right panel) appear to respond significantly positively to government spending shocks in the GR period. Both series show similar responses across the underlying sample. Inflation and expected inflation rise strongly in response to an increase in government expenditures in the late 1960ies and at the beginning of the 1970ies. Afterwards, the results indicate a mild deflationary effect of fiscal policy, although the responses are not statistically different from zero. However, at the end of the sample and especially during the period of the GR, there is indeed a positive response of (expected and realized) inflation. The rise in actual inflation is somewhat larger than its expected counterpart, but both responses are statistically significant. Thus, these findings indicate that the first 
Figure 5: average inflation and expected inflation responses.
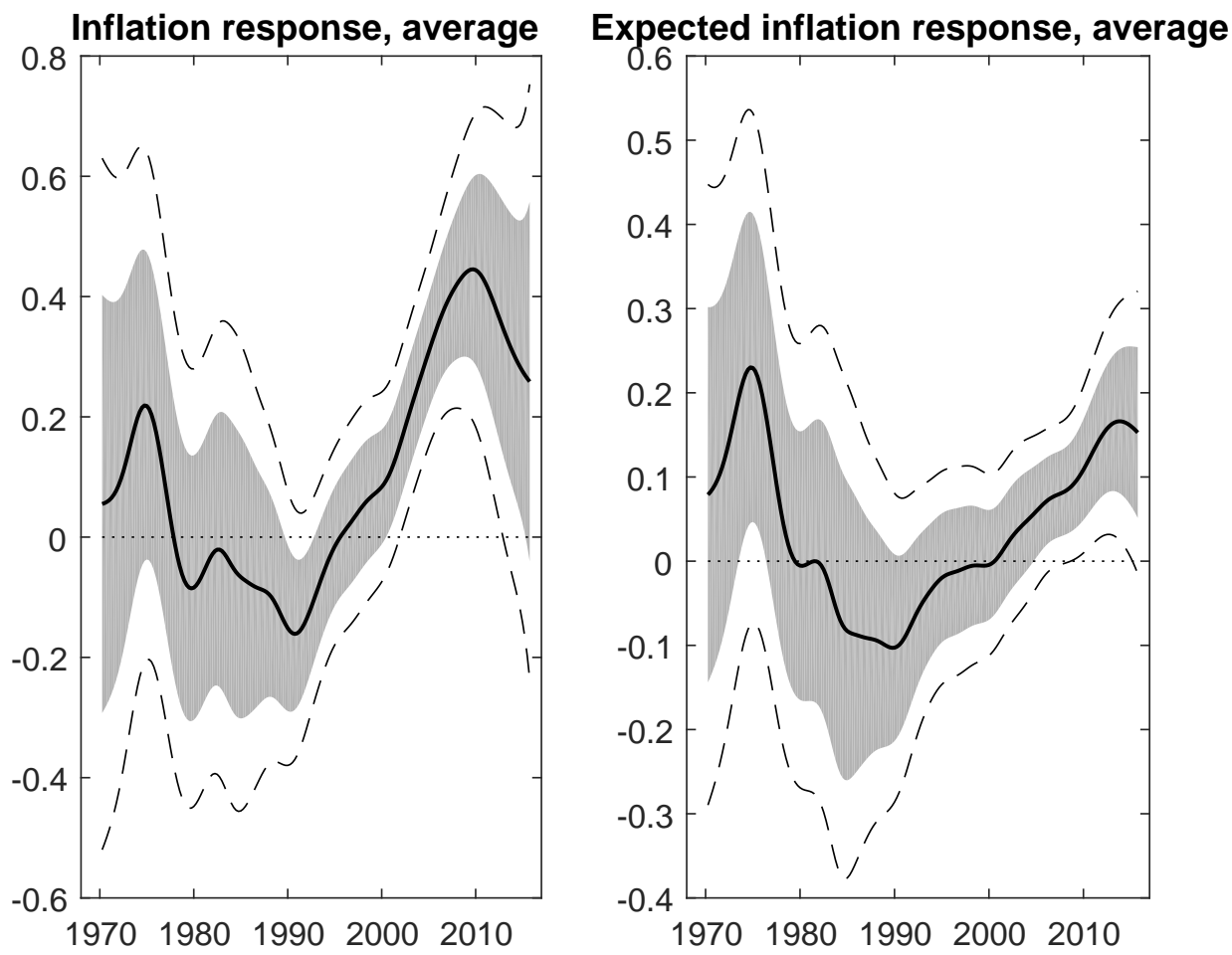

Notes: Solid lines show mean responses. Shaded areas and dashed lines indicate $68 \%$ and $90 \%$ bootstrapped confidence intervals.

part of the New Keynesian explanation, according to which government spending at the ZLB works through higher expected inflation, receives some empirical support.

However, the evidence is less favorable for the second part of the theory, which implies that higher inflation following an increase in government spending should lead to lower real interest rates when the ZLB binds. In Figure 6, we show the response of the model implied short-run real interest rate (we will discuss robustness with respect to other real interest rate measures below). In each case, this response is constructed as the difference between the responses between the nominal short-run (shadow) interest rate and an inflation variable. In the left panel of Figure 6, the inflation variable used is realized inflation, such that the response of the implied ex-post real interest rate is shown. In the right panel, we used the expected inflation variable to construct the implied ex-ante real interest rate. As can be seen from Figure 6, the model implied real interest rate rose, rather then fell, in the GR period. The response is economically sizeable and also statistically significant in this phase, whereas it is very small and clearly insignificant in all other periods. Thus, for the period before the GR we do not find clear evidence of significant changes between accommodative and restrictive monetary policy in response to government spending shocks. The results rather imply that monetary policy has typically offset the implied increase in inflation one-to-one by a rise in interest rates.

Most important for our purpose is the fact that in no case is there any evidence that government spending shocks had a negative effect on the real interest rate in the GR 
Figure 6: implied real interest rate responses.
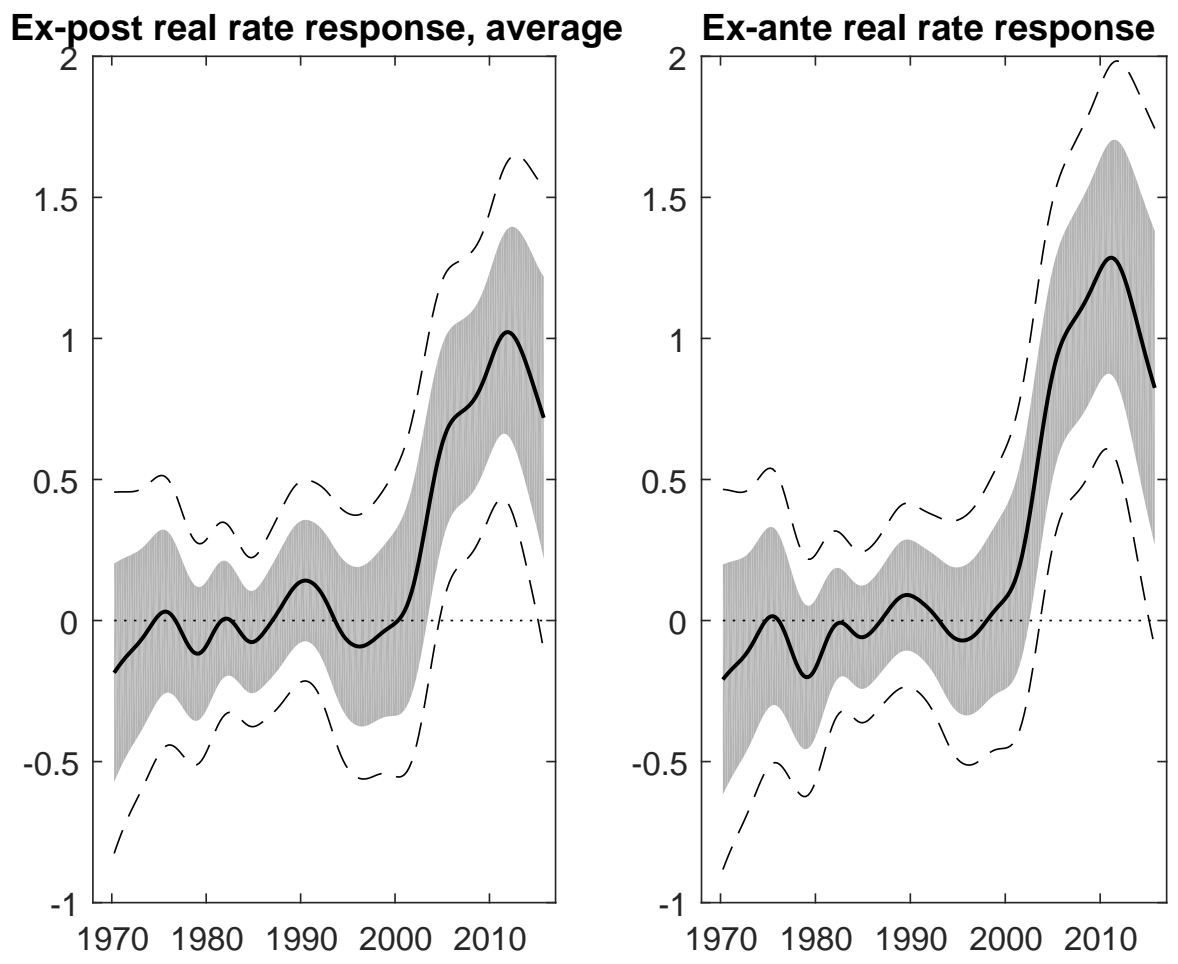

Notes: Solid lines show mean responses. Shaded areas and dashed lines indicate $68 \%$ and $90 \%$ bootstrapped confidence intervals.

period or its aftermath. Thus, it does not appear to be the case that higher than normal fiscal policy effectiveness with respect to output stimulation in the GR can be explained, as in the New Keynesian view, through a lowering of real interest rates.

Two remarks are in order. First, the results shown in Figure 6 are surprising at first sight, since because inflation appears to have responded positively to fiscal shocks in the GR, a positive real interest rate response implies an even more strongly positive nominal interest rate response. Of course, it is well known that, unconditionally, nominal interest rates did not increase in the GR. However, the impulse responses that we report are conditional statements. The interpretation is that interest rates would have risen in the GR episode if only positive fiscal shocks had occured then, but remained low due to other shocks hitting the economy. ${ }^{9}$ Second, these results are obtained by using the shadow rate as the short-run nominal interest rate, which turns negative in the GR and slowly recovers thereafter. Since the shadow rate is a constructed variable rather than an observed one, it could be the case that measurement errors induce a misleading conditionally positive relation between the implied real rate and fiscal shocks. However, the results are qualitatively the same, and quantitatively similar, if the shadow rate is replaced by the observed Federal Funds Rate, or a by a longer term treasury interest rate (results for nominal and real long-term government bond interest rate responses are shown in the online Appendix).

\footnotetext{
${ }^{9}$ While it would be interesting to assess the contribution of fiscal shocks to a possible solution of the 'missing disinflation puzzle', i.e. the failure of inflation to decline more strongly in the GR, this is beyond the scope of this paper.
} 
Overall, our findings suggest that the increased effectiveness of fiscal policy during the GR cannot be rationalized by a decrease in the real interest rate.

More importantly, we can use our estimates to uncover another type of mechanism of fiscal transmission through interest rates that is somewhat different to the baseline New Keynesian story. We ask whether fiscal policy was effective in lowering interest rate spreads during the GR episode. In Figure 7, we report the average impulse response of the spread between BAA rated corporate bond yields and long-term (10 year) government bond yields.

Figure 7: corporate-to-government bond yield spread responses.

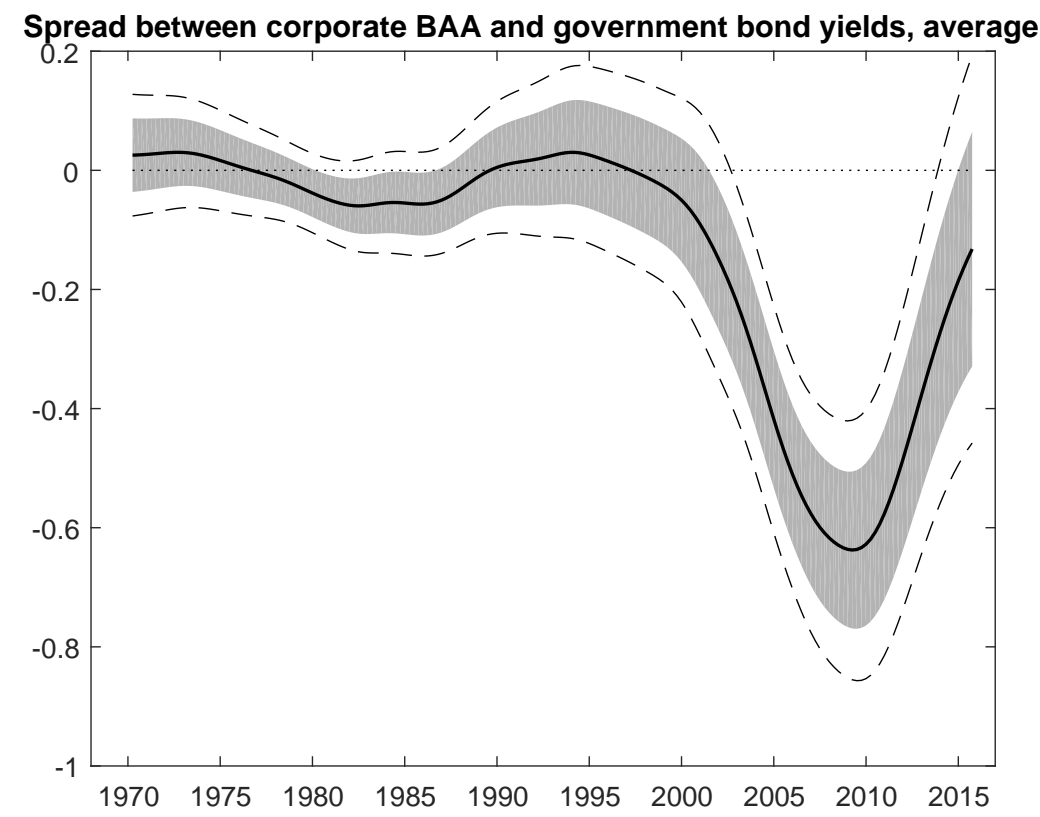

Notes: Solid lines show mean responses. Shaded areas and dashed lines indicate $68 \%$ and $90 \%$ bootstrapped confidence intervals.

Figure 7 shows that the corporate-over-government bond spread was hardly affected by government spending shocks in earlier times. In contrast, the spread conditionally declined significantly and strongly in the GR. Thus, while the real interest rate as measured by a short monetary policy rate tended to increase, the private interest rate premium measured by the corporate bond yield was strongly lowered through fiscal shocks as evident from Figure 7.

Arguably, the spread between BAA rated corporate bond yields and government bond yields is mostly influenced by the perceived risk of default in the private sector. Hence, a possible interpretation of a strong decline in this spread in response to positive government shocks is that higher government spending prevented aggregate goods demand from declining further and thus lowered the risk of widespread private sector defaults. The resulting lower private to government interest rate spread could thus have relaxed financing constraints of firms, allowing them to limit the reduction in investment and production. This finding suggests that fiscal policy may have been able to considerably reduce financial frictions by lowering corporate credit costs. In light of the theoretical contribution by 
Canzoneri et al. (2016), this result may explain the large output responses to government spending presented above. Using a DSGE model with financial frictions in the corporate sector, these authors show that a reduction in corporate spreads induced by higher government expenditures increases the size of the spending multiplier. Our results are in line with the view that the impact of fiscal policy is amplified in a situation when the policy intervention improves the financing conditions of corporate borrowers. Since the corporate bond rate was well above zero in the whole sample including the GR (its sample minimum being $4.5 \%$ ), this view implies that it is not the ZLB that has rendered fiscal policy unusually effective. Rather, it seems that the effect of fiscal spending has been supported by some type of financial accelerator mechanism, in that higher government demand was able to lower financial frictions, as witnessed by the private bond spread decline, and thus had a higher than normal effect on aggregate demand. In this regard, our finding of large output responses to government spending shocks during the GR is more in line with the New Keynesian model version enriched by corporate financial frictions as suggested by Canzoneri et al. (2016).

If government spending has indeed mitigated the bite of financial frictions in the GR, then it is likely that it should have supported private investment. In many models with financial frictions, investment by firms is the variable most directly and strongly affected by financial shocks or the tightening of financial conditions. Indeed, a common interpretation of what happened in the GR is that after initial losses in mortgage financing the crisis spread through sharply declining lending both among banks and to goods producing firms due to increased counterparty default risk. The resulting drop in corporate investment contributed to the demand decline. Now if government spending was able to reduce the risk premium on corporate borrowing, as suggested by Figure 7 above, then it should have enabled corporate investment spending that would otherwise not have taken place.

To analyze whether this view of the transmission could be correct, we present the average time varying response of real private investment in the left panel of Figure 8 . Between the beginning of the 1960ies and the end of the 1970ies, investment declined in response to a government spending shock. At the end of the 1980ies, investment shows an increase but the response turns again negative thereafter. For the period of the GR, we indeed find that government spending has led to an increase in investment. Although the point estimates are consistent with the interpretation that reduced corporate spreads may have led to an increase in private investment, these results should be interpreted with caution as confidence bands are quite large and the average investment response is statistically insignificant throughout. Thus, the ultimate relevance of the possible financial accelerator channel of fiscal policy sketched above is unfortunately difficult to assess from these results.

However, while there is rather large statistical uncertainty around the effect of fiscal policy on investment demand, the effect on private consumption demand which is shown in 
Figure 8: average investment, consumption, and confidence responses.
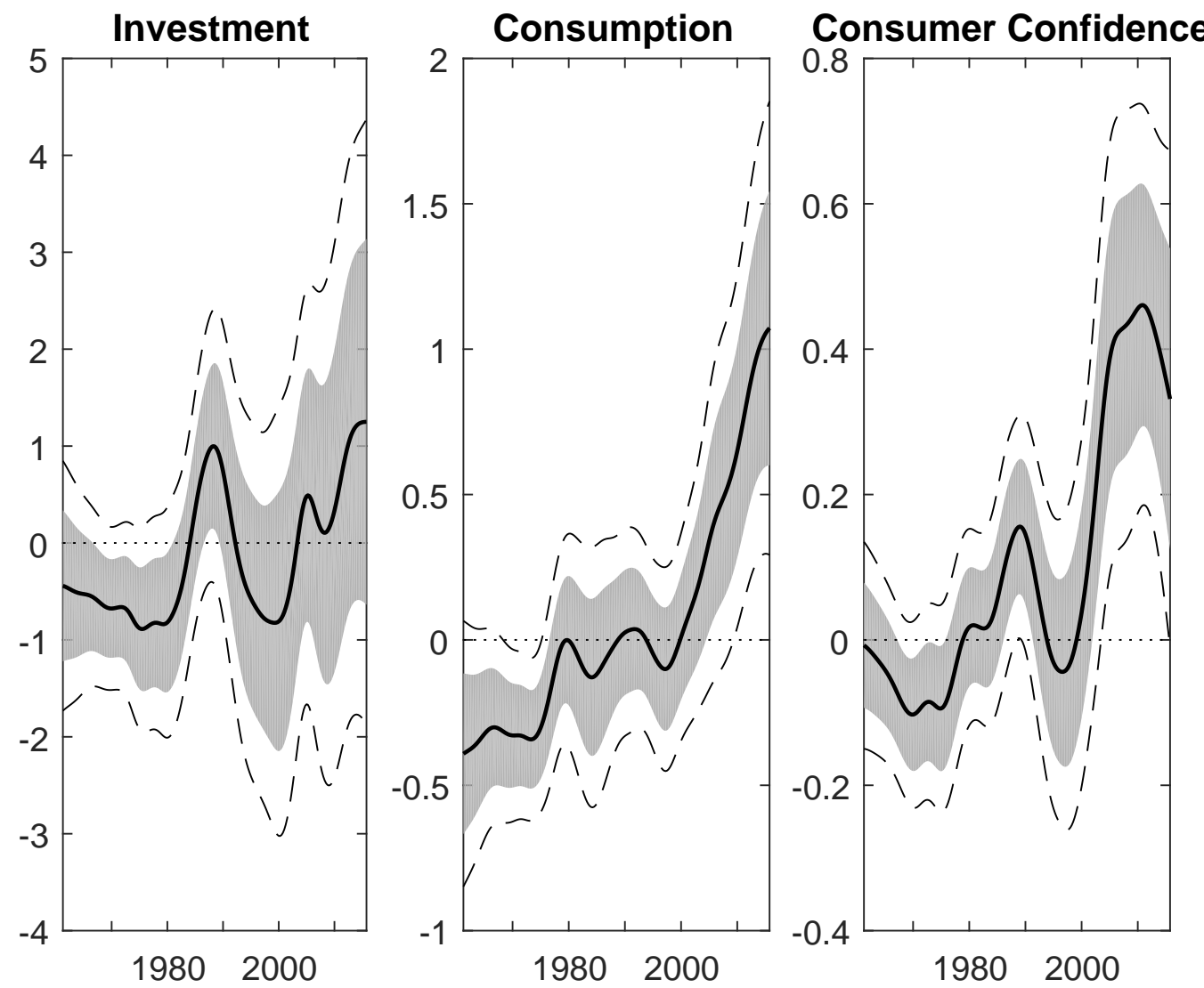

Notes: Solid lines show mean responses. Shaded areas and dashed lines indicate $68 \%$ and $90 \%$ bootstrapped confidence intervals.

the middle panel of Figure 8 seems more precisely estimated in many parts of the sample. While the private consumption response is always estimated to be negative until the beginning of the 2000s, and sometimes significantly so, there is a sizeable and statistically significant positive effect in the later sample part. Thus, government spending seems to have crowded in private consumption in the period dominated by the GR.

This finding is interesting in its own right, since it is well known that in many models private consumption should react negatively if the government claims a larger part of the economy's resources for its own use. Most of the time, this intuition seems to be borne out by the empirical results. Hence, the question arises why the relation between public spending and private consumption seems to have turned around more recently. A possible answer is suggested by the result shown in the right panel of Figure 8. There, we present the average impulse response of a survey-measured index of consumer confidence. We use data from the Michigan Survey of Consumers. The survey polls a nationally representative sample of households on a variety of questions concerning personal and aggregate economic conditions. In the following, we focus on the Index of Consumer Sentiment.

The reason for looking at consumer confidence is suggested by a recent literature starting with Bachmann and Sims (2012). These authors argue for the existence of a 'confidence channel' of fiscal policy. They show that government spending is more effec- 
tive in stimulating the economy when it also leads to a significant increase in consumer confidence. Moreover, they find that the strength of this effect crucially depends on the state of the business cycle: significant increases in confidence and large fiscal multipliers during recessions are accompanied by no significant confidence response and small fiscal multipliers during economic expansions. In a similar vein, Beetsma et al. (2015) show that changes in private sector confidence in response to fiscal consolidations are important to understand how fiscal budget consolidation efforts affects economic activity. Guimares et al. (2016) study the confidence channel in a theoretical framework. In their model equilibrium, the private sector fails to achieve the optimal level of aggregate demand. An increase in government spending affects agents' beliefs which ultimately provides a boost to private demand. More generally, Barsky and Sims (2012) show that an increase in confidence leads to a significant and sizeable rise in private consumption.

As can be seen in the right panel of Figure 8, according to our estimates there is only a small and mostly insignificant effect of government spending shocks on consumer confidence most of the time. However, in the later parts of the sample, confidence rises strongly and significantly in response to a government spending shock. The average response shows an increase in consumer confidence of around 0.5 percentage points during the GR and in the following years. The point estimates during that episode is substantially larger compared to earlier periods of the sample. This evidence can be interpreted as supporting the existence of a confidence channel of fiscal policy as proposed by Bachmann and Sims (2012). Government spending shocks during the GR had a strong positive effect on consumer confidence, a finding that may explain why the output and consumption responses are amplified during this period. Note that, in contrast to Bachmann and Sims (2012), we do not find that the confidence response regularly depends on the state of the business cycle. In fact, our results indicate that the responses observed during the GR are not a general finding present during periods of high economic slack.

Note that outside the GR the only other markedly positive and significant response of consumer confidence occurs in the late 1980ies, where it is accompanied by a clearly higher than normal and borderline significant investment response. As can be seen by comparison with Figure 1 above, these changes coincide with a relatively large output response. This could point to a more general influence of confidence, or more broadly sentiments, in shaping the size of responses to policy shocks, though this interpretation remains tentative since consumption itself does not appear to react much at all in this time frame.

So far we have mainly concentrated on how government spending shocks affect aggregate economic activity. However, there are also other variables whose response to fiscal policy interventions is of interest. We now focus on how the exchange rate, unemployment rate and two other important fiscal variables namely, the government debt-to-GDP ratio and the fiscal deficit-to-GDP ratio, react to a government spending shock. The fiscal deficit 
Figure 9: other variables of interest.
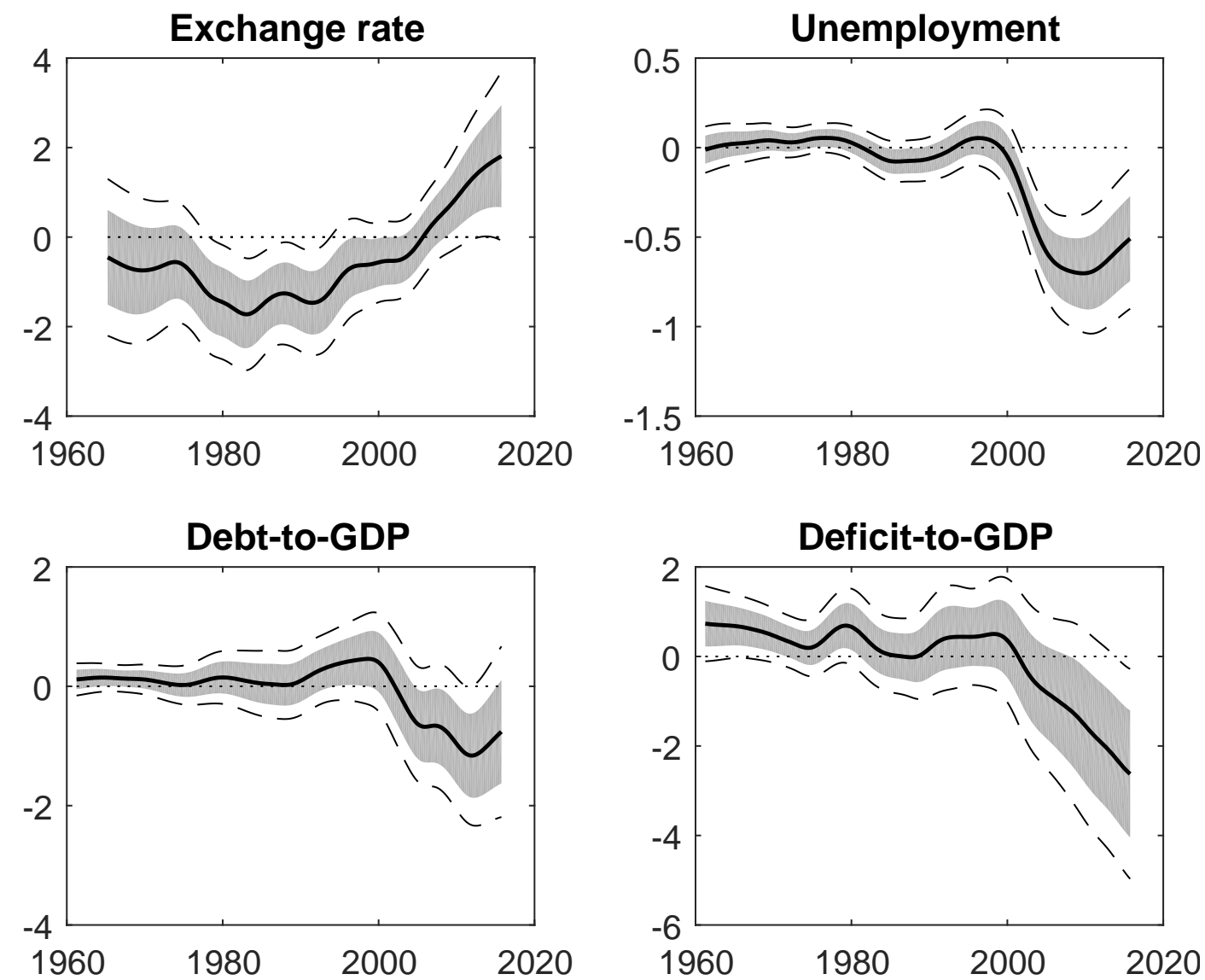

Notes: Solid lines show mean responses. Shaded areas and dashed lines indicate $68 \%$ and $90 \%$ bootstrapped confidence intervals.

is defined as the difference between total government expenditures and government tax revenues. Figure 9 shows the respective average responses. It is evident that government spending shocks during the period of the GR had a particular effect on all these variables. As shown in the upper left panel of Figure 9, the real effective exchange rate depreciated in response to a government spending shock in most parts of the sample. ${ }^{10}$ However, during the GR episode, a government spending shock led to an appreciation in the exchange rate. This result is of interest on its own because there exists mixed evidence on the exchange rate response to a government spending shock. Our findings suggest that time-variation could potentially play a role for explaining these conflicting findings. ${ }^{11}$ However, the output effect of fiscal policy in the GR is unlikely to have worked through the exchange rate channel, as the real appreciation would tend to reduce export demand and possibly exert a negative wealth effect through the revaluation of foreign currency denominated assets as discussed in Gourinchas and Rey (2007).

As shown in the upper right panel of Figure 9, until, the 1980ies, fiscal shocks appear neither to have had an economically sizeable nor statistically significant effect on the

\footnotetext{
${ }^{10}$ The exchange rate is defined such that an increase indicates a real appreciation.

${ }^{11}$ Thanks are due to an anonymous referee for pointing this out. An example for a study that finds that a government spending shock leads to an appreciation in the exchange rate is Abbas et al. (2011), while for example Enders et al. (2011) find the opposite.
} 
unemployment rate. There is a strongly negative effect, however, during the GR, which mirrors the output effect of government shocks reported above with the opposite sign. The lower left and right panel of Figure 9 show the responses of the public debt-to-GDP ratio and the fiscal deficit-to-GDP ratio, respectively. Both responses display notable timedependence. While higher government spending usually leads to an increase in the debtto-GDP ratio and the fiscal deficit, as expected, this is reversed strongly and significantly at the end of the sample. During the GR and its aftermath, government spending is estimated to have been essentially self-financing. A similar result is found by Auerbach and Gorodnichenko (2017). Using a large panel of countries, they show that during recessions an increase in government spending leads to a significant reduction in the public debt burden.

\subsection{State or time dependence?}

In the literature, there is a debate whether government spending shocks have larger output effects in recession as opposed to business cycle expansions (see e.g., Auerbach and Gorodnichenko, 2012; Ramey and Zubairy, 2017). We have established above that there is noteworthy time dependence in the effects of fiscal shocks. In this section, we ask if the time variation that we have estimated is evidence of state dependence of fiscal effects, in the sense that the output response is related to the state of the business cycle.

Figure 10 shows the output response over all NBER recessions in the sample. The timevarying impulse responses are in each case averaged over the duration of the respective NBER recession episode. For comparison, in each panel the solid line without markers gives the response that would be estimated from a constant parameters specification.

\section{Figure 10: output responses during NBER recessions.}
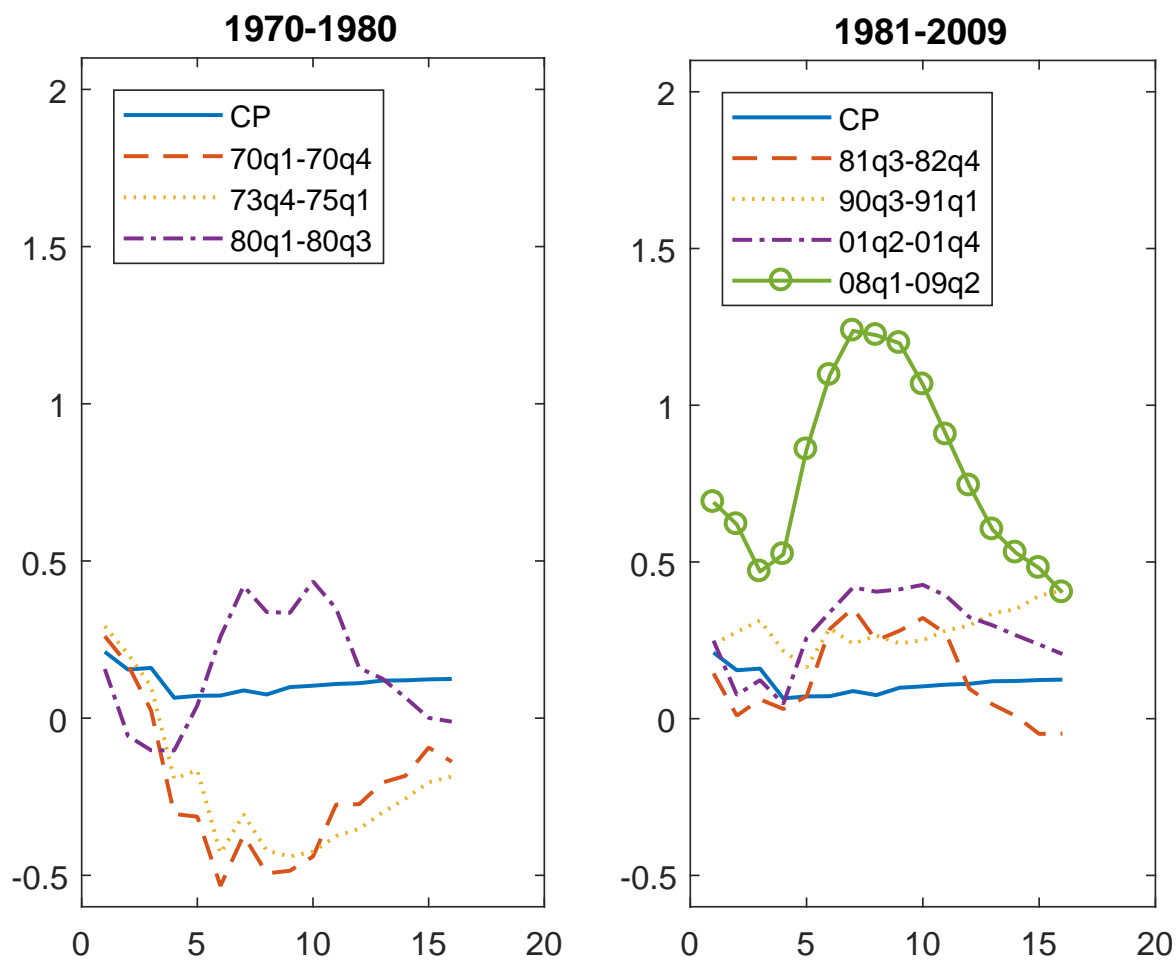
Figure 10 shows that the shorter run effects of fiscal shocks are quite similar in the NBER recessions with the notable exception of the GR. While there is much more variation at longer response horizons, particularly in the earlier sample half, there is no clear pattern discernible outside the GR. Thus, we do not find any evidence that output effects of fiscal shocks are systematically different in NBER recessions. Instead, it appears that the GR period was unusual with respect to fiscal transmission.

Of course, NBER recessions, while widely used, are not the only possibility to define the state of the business cycle. In Table 1, we therefore show the impact and eight quarter average output response additionally for other possible definitions of the cyclical situation, namely whether the unemployment rate is below or above a certain threshold (lines 3 and 4 in Table 1), or whether the growth rate of real GDP is above or below its sample mean (lines 5 and 6 in Table 1). Following Ramey and Zubairy (2017), we choose an unemployment rate threshold of $6.5 \%$. The first two columns in Table 1 present the results for the whole sample, whereas the two rightmost columns show the same statistics for a sample that stops right before the turbulence that started in the year 2008 .

\begin{tabular}{|c|c|c|c|c|c|}
\hline & & \multicolumn{2}{|c|}{ full sample } & \multicolumn{2}{|c|}{ before 2008} \\
\hline & cyclical indicator $\downarrow$ & impact & average $8 \mathrm{q}$ & impact & average $8 \mathrm{q}$ \\
\hline 1. & no NBER recession & 0.3104 & 0.2076 & 0.2335 & 0.1341 \\
\hline 2. & NBER recession & 0.3140 & 0.2032 & 0.2237 & 0.0504 \\
\hline 3. & unemployment rate $<6.5 \%$ & 0.2840 & 0.1495 & 0.2476 & 0.1201 \\
\hline 4. & unemployment rate $\geq 6.5 \%$ & 0.3596 & 0.3108 & 0.1961 & 0.1296 \\
\hline 5. & GDP growth above mean & 0.2507 & 0.1301 & 0.2142 & 0.0934 \\
\hline 6. & GDP growth below mean & 0.3717 & 0.2844 & 0.2543 & 0.1591 \\
\hline
\end{tabular}

Looking at the full sample results, there seems to be a notable difference in the output effects of fiscal spending shocks between periods of low or high unemployment, and similarly between periods of above or below average GDP growth. While there is some variation in the impact effects, the most remarkable difference is clearly seen over the longer response horizon, as witnessed by the fact that the average impulse responses are more than twice as large in periods of high unemployment or low growth. This could be interpreted as a finding corroborating the view in Auerbach and Gorodnichenko (2012) that the effects of fiscal impulses are larger in recessions than in booms.

However, looking at the pre-2008 results in the right part of Table 1 shows that a large part of the apparent business cycle dependence in the output responses seems to be due to the GR and its aftermath. The average output response in high unemployment times before 2008 was practically the same as the one in low unemployment times. The difference in the output response between low and high GDP growth phases does not vanish when confining the analysis to the pre-2008 sample, however, even though the difference is much less pronounced than when taking the whole sample into account. 
Our conclusion from these results is twofold. First, the evidence for business cycle dependence of fiscal shock effects seems mixed and rather inconclusive. This finding is, of course, not new, since it is already underlying the difference between the views expounded in Auerbach and Gorodnichenko (2012) and Ramey and Zubairy (2017). Second, however, we conclude that obviously not all business cycles are alike in how they affect the workings of fiscal policy. In particular, whatever the effect of the average business cycle on fiscal policy effectiveness may be, the GR stands out as a highly unusual period characterized by arguably the largest change in the effects of government spending on output in the sample. This implies that defining one specific indicator variable and constructing average responses across all recessions and booms as applied by Auerbach and Gorodnichenko (2012) and Ramey and Zubairy (2017) most likely misses the particularity of the Great Recession episode.

\section{Conclusion}

This paper reveals important time variation in the effect of government spending shocks on the US economy. Estimating time-varying parameter vector autoregressions, we find that while there is some variation in the economy's response to government spending shocks in several periods, by far the largest change occur in the years surrounding the Great Recessions. The effectiveness of fiscal policy interventions is considerably amplified during that episode resulting in output responses that are roughly three times as large compared to an estimation which restricts the parameters to be time-invariant. This finding is robust to different ways of identifying government spending shocks. Additionally, we find that during that period an increase in government spending has also led to a significant fall in the unemployment rate and has been essentially self-financing.

We provide evidence that our results can not be rationalized by the New Keynesian model which predicts a decline in the real interest rate in response to an increase in government spending when the economy is subject to the zero lower bound. Although, we do find that expansionary fiscal policy was able to lift up inflation during the Great Recession period, the real interest rate increased rather then fell. We highlight two additional channels that are able to explain our baseline findings. First, during the Great Recession a rise in public expenditures significantly reduced the spread between corporate and government bond yield supporting the financial accelerator mechanism as pointed out by Canzoneri et al (2016). Second, we find that a that positive government spending innovation has increased consumer sentiment during that episode, a result that supports the confidence channel channel of fiscal policy recently suggested by Bachmann and Sims (2012), Beetsma et al. (2015) and Guimaraes et al. (2016). Indeed, our evidence suggests that future work should elaborate more on financial frictions and changes in confidence when studying fiscal policy interventions. 


\section{References}

Abbas, A., J. Bouhga-Hagbe, A. Fatás, P. Mauro, and R. C Velloso (2011), Fiscal Policy and the Current Account, IMF Economic Review 59, 603-629.

Auerbach, A. J., and Y. Gorodnichenko (2012), Measuring the Output Responses to Fiscal Policy, American Economic Journal: Economic Policy 4, 1-27.

Auerbach, A. J., and Y. Gorodnichenko (2017), Fiscal Stimulus and Fiscal Sustainability, NBER Working Papers 23789.

Bachmann, R., and E. R. Sims (2012), Confidence and the transmission of government spending shocks, Journal of Monetary Economics 59, 235-249.

Barsky, R. B., and E. R. Sims (2012), Information, animal spirits, and the meaning of innovations in consumer confidence, American Economic Review 102, 1343-1377.

Beetsma, R., J. Cimadomo, O. Furtuna, and M. Giuliodori (2015), The confidence effects of fiscal consolidations, Economic Policy 30, 439-489.

Ben Zeev, N., and E. Pappa (2017), Chronicle of a War Foretold: The Macroeconomic Effects of Anticipated Defence Spending Shocks, Economic Journal 127, 1568-1597.

Bilbiie, F. O., A. Meier, and G. Müller (2008), What Accounts for the Changes in U.S. Fiscal Policy Transmission?, Journal of Money, Credit and Banking 40, 1439-1470.

Blanchard, O., and D. Leigh (2013), Growth Forecast Errors and Fiscal Multipliers, American Economic Review 103, 117-120.

Blanchard, O., and R. Perotti (2002), An Empirical Characterization of the Dynamic Effects of Changes in Government Spending and Taxes on Output, The Quarterly Journal of Economics 117, 1329-1368.

Canova, F., and E. Pappa (2011), Fiscal Policy, Pricing Frictions and Monetary Accommodation, Economic Policy 26, 555-598.

Canzoneri, M., F. Collard, H. Dellas, and B. Diba (2016), Fiscal Multipliers in Recessions, Economic Journal 126, 75-108.

Chodorow-Reich, G., L. Feiveson, Z. Liscow, and W. G. Woolston (2012), Does State Fiscal Relief During Recessions Increase Employment? Evidence from the American Recovery and Reinvestment Act, American Economic Journal: Economic Policy 4, 118-145.

Christiano, L., E. Eichenbaum, and S. Rebelo (2011), When Is the Government Spending Multiplier Large?, Journal of Political Economy 119, 78-121.

Davig, T., and E. M. Leeper (2011), Monetary-Fiscal Policy Interactions and Fiscal Stimulus, European Economic Review 55, 211-227.

Eggertsson, G. (2011), What Fiscal Policy is Effective at Zero Interest Rates?, NBER Chapters, in: NBER Macroeconomics Annual 2010, Volume 25, 59-112.

Enders, Z., G. J. Müller, and A. Scholl (2011), How do fiscal and technology shocks affect real exchange rates?: New evidence for the United States, Journal of International Economics 83, 53-69.

Fernández-Villaverde, J. (2010), Fiscal Policy in a Model with Financial Frictions, 
American Economic Review, 100, 35-40.

Gertler, M, and P. Karadi (2015), Monetary Policy Surprises, Credit Costs, and Economic Activity, American Economic Journal: Macroeconomics 7, 44-76.

Giraitis, L., G. Kapetanios, and T. Yates (2014), Inference on stochastic time-varying coefficient models, Journal of Econometrics 179, 46-65.

Giraitis, L., G. Kapetanios, K. Theodoridis, and T. Yates (2015), Estimating timevarying DSGE models using minimum distance methods, Queen Mary University, School of Economics and Finance, Working Paper No. 768.

Gourinchas, P.-O., and H. Rey (2007), From world banker to world venture capitalist: US external adjustment and the exorbitant privilege, in: G7 Current Account Imbalances: Sustainability and Adjustment, University of Chicago Press, 11-66.

Guimaraes, B., C. Machado, and M. Ribeiro (2016), A Model of the Confidence Channel of Fiscal Policy, Journal of Money, Credit and Banking 48, 1363-1395.

Ilzetzki, E., E. G. Mendoza, and C. A. Végh (2013), How big (small?) are fiscal multipliers?, Journal of Monetary Economics 60, 239-254.

Jordá, Ó. (2005), Estimation and Inference of Impulse Responses by Local Projections, American Economic Review 95, 161-182.

Leeper, E. M., N. Traum, and T. B. Walker (2017), Clearing Up the Fiscal Multiplier Morass, American Economic Review 107, 2409-2454.

Miyamoto, W., T. L. Nguyen, and D. Sergeyev (2017), Government Spending Multipliers under the Zero Lower Bound: Evidence from Japan, American Economic Journal: Macroeconomics, forthcoming.

Owyang, M. T., V. Ramey, and S. Zubairy (2013), Are Government Spending Multipliers Greater during Periods of Slack? Evidence from Twentieth-Century Historical Data, American Economic Review 103, 129-134.

Primiceri, G. E. (2005), Time Varying Structural Vector Autoregressions and Monetary Policy, The Review of Economic Studies 72, 821-852.

Ramey, V. (2011), Identifying Government Spending Shocks: It's all in the Timing, The Quarterly Journal of Economics 126, 1-50.

Ramey, V., and S. Zubairy (2017), Government Spending Multipliers in Good Times and in Bad: Evidence from U.S. Historical Data, Journal of Political Economy, forthcoming.

Shoag, D. (2013), Using State Pension Shocks to Estimate Fiscal Multipliers since the Great Recession, American Economic Review 103, 121-124.

Wu, J. C. and Xia, F. D. (2016), Measuring the Macroeconomic Impact of Monetary Policy at the Zero Lower Bound, Journal of Money, Credit and Banking 48, 253-291. 


\section{Appendix}

\section{A1 Time-varying output response}

The following Figure A1 shows the time-varying percentage response of real GDP to a one percentage point shock to real government spending.

Figure A1: Time-varying output responses to government spending shock.

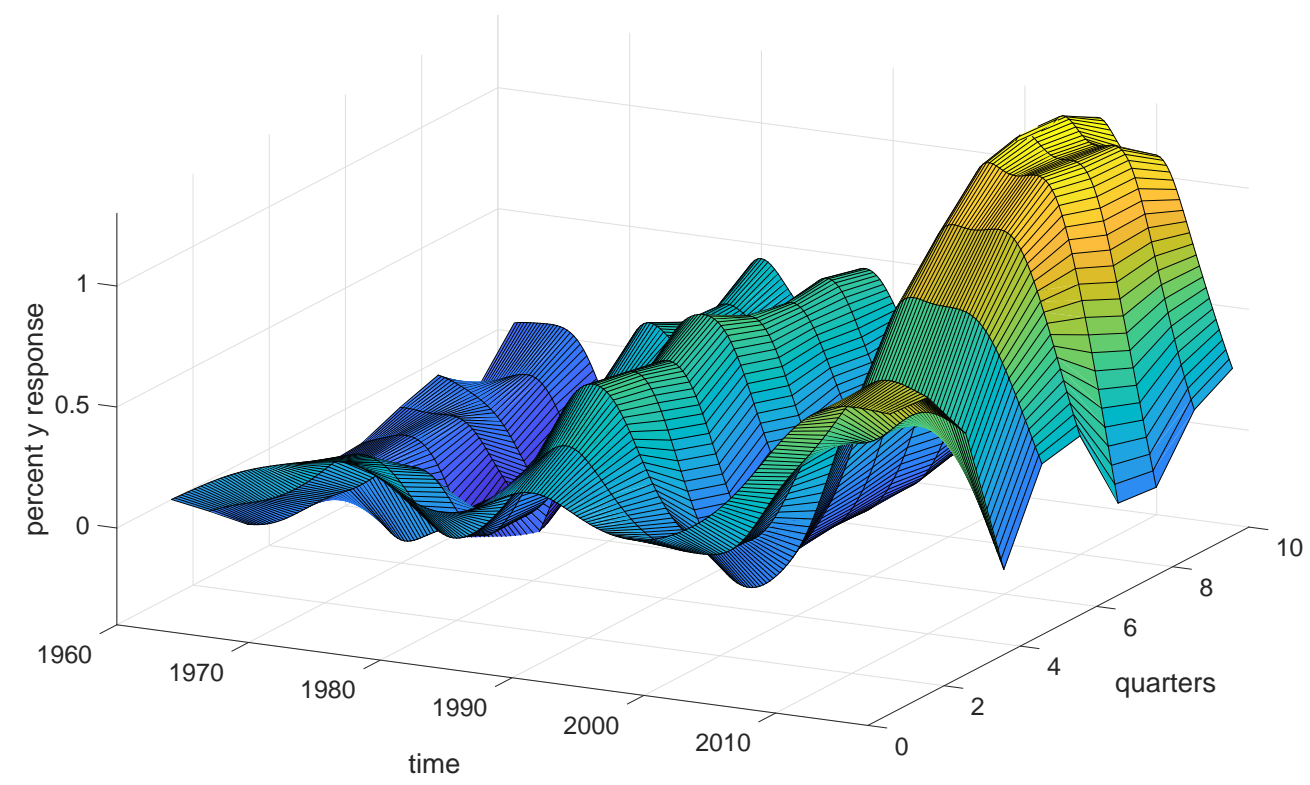




\section{A2 Six variables VAR}

The following figure A2 presents impact and average output responses from a time-varying VAR with six variables that excludes the spread and confidence series. The responses are comparable to our baseline (eight variable) specification.

Figure A2: Small VAR.
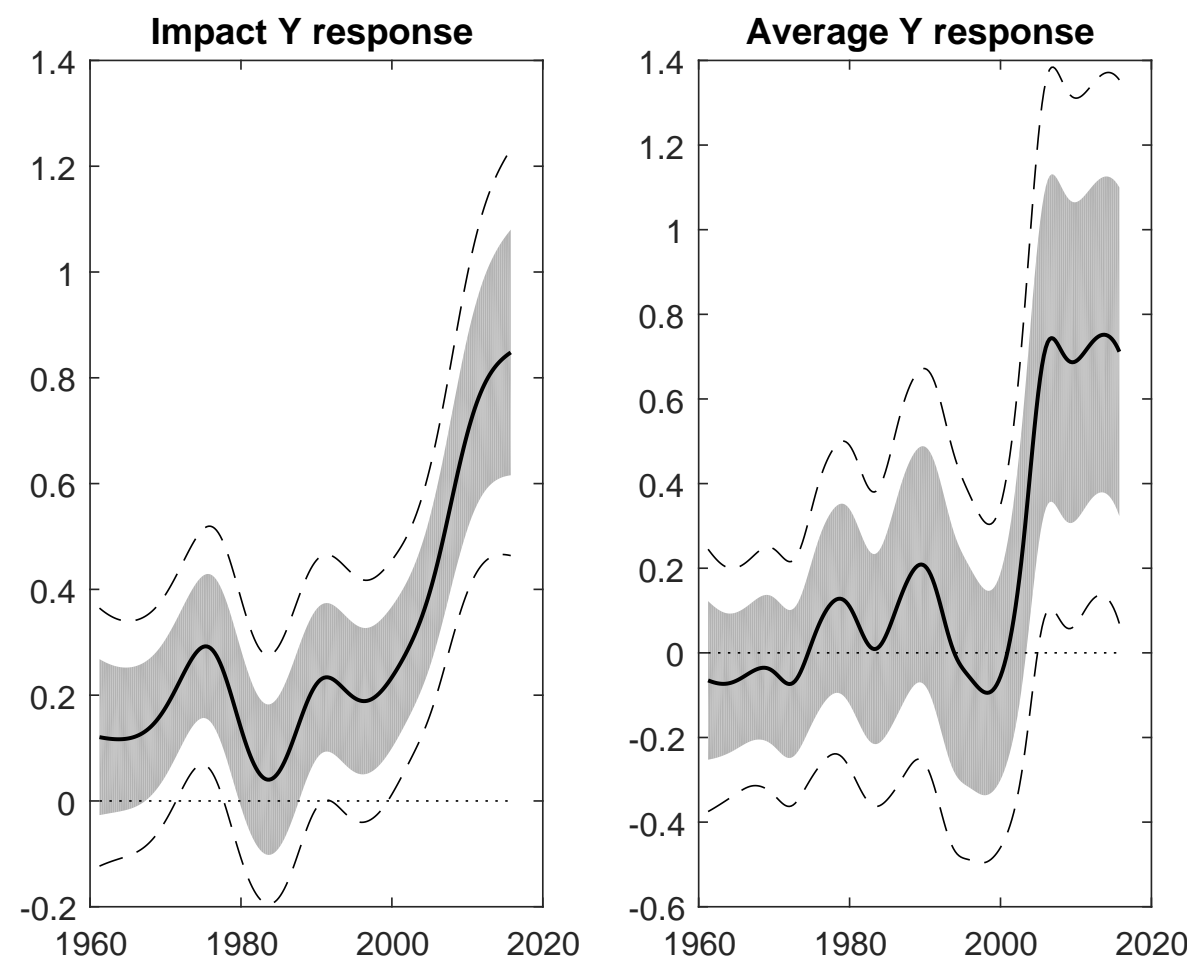

Notes: Solid lines show mean responses. Shaded areas and dashed lines indicate $68 \%$ and $90 \%$ bootstrapped confidence intervals. 


\section{A3 Per-capita series}

Figure A3 shows the impact and average output responses from a time-varying VAR that uses real government spending and output in per-capita terms. The responses are very close to those of our baseline specification.

Figure A3: Per capita series.
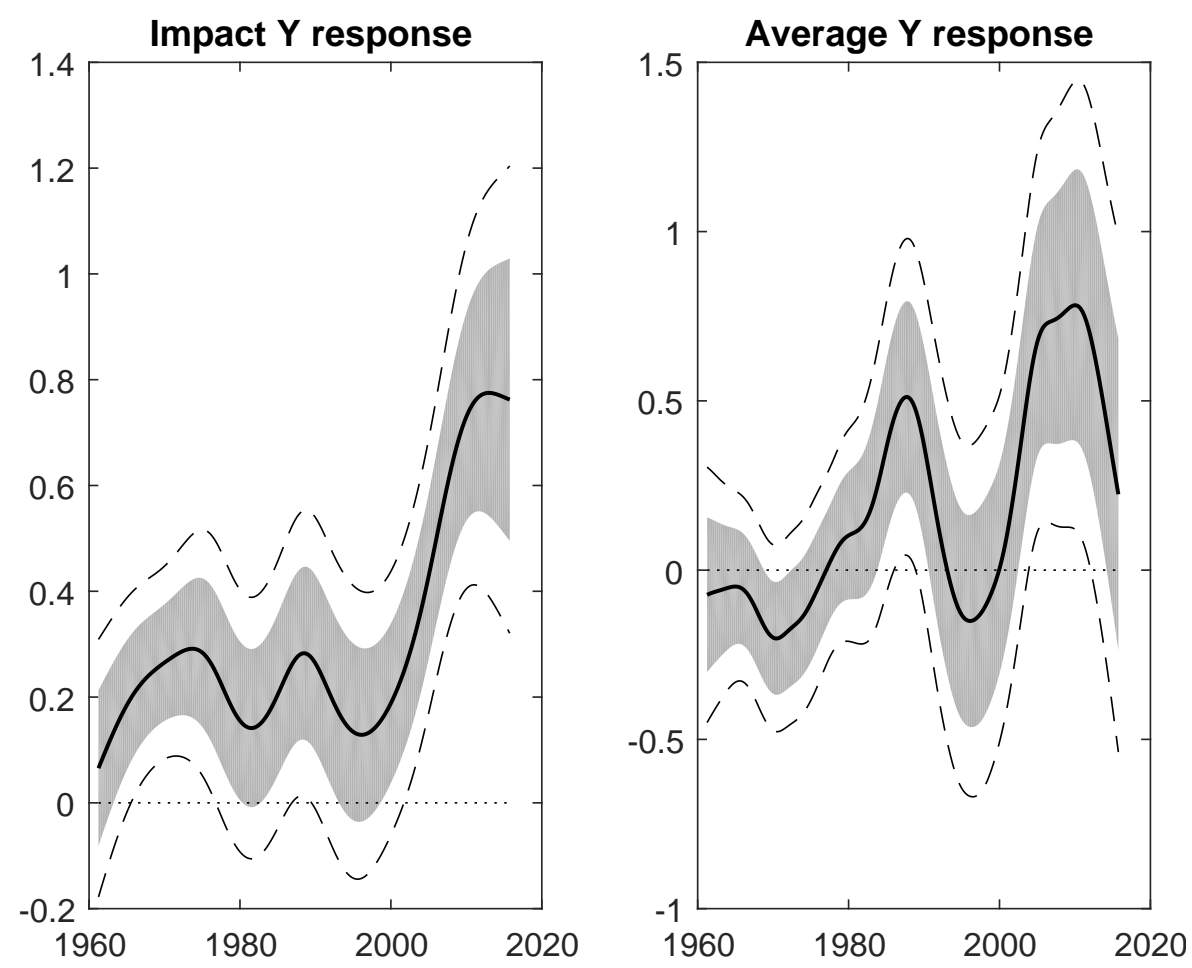

Notes: Solid lines show mean responses. Shaded areas and dashed lines indicate $68 \%$ and $90 \%$ bootstrapped confidence intervals. 


\section{A4 Kernel weighting function}

The following Figure A4 shows the Gaussian kernel weighting function $k_{t j}$ used in the estimation for two example sample points, one at $t=100$ and the other at $t=T$ where $T$ is the sample size.

Figure A4: Kernel weight.

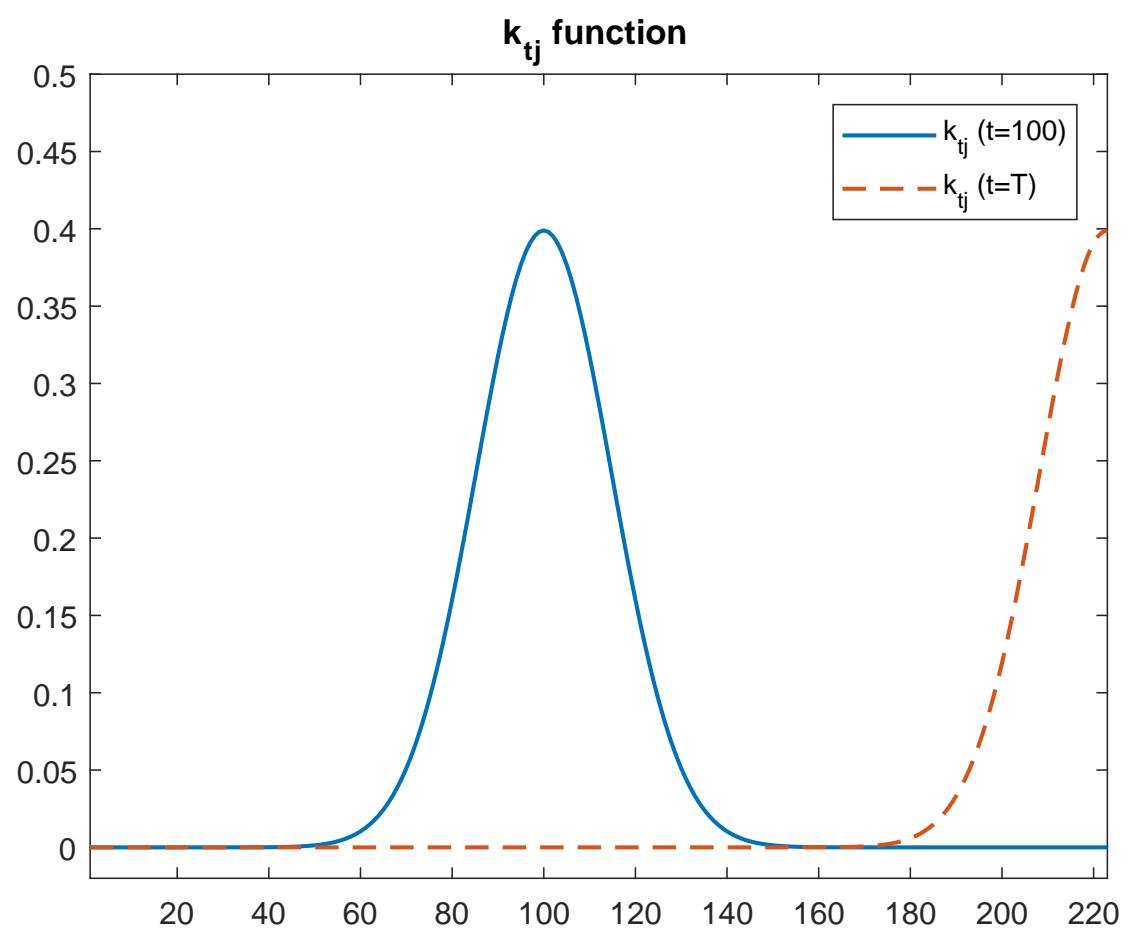




\section{A5 Varying the sample end point}

We simulate triangular bivariate VAR model to generate 210 sample observations from

$$
\begin{aligned}
& C_{01} x_{t}=C_{11} x_{t-1}+\varepsilon_{t} \text { for } t<70 \text { or } 140<t \leq 210 \\
& C_{02} x_{t}=C_{12} x_{t-1}+\varepsilon_{t} \text { for } 70 \leq t \leq 140
\end{aligned}
$$

where

$$
C_{01}=\left(\begin{array}{rr}
1 & 0 \\
-0.2 & 1
\end{array}\right), C_{02}=\left(\begin{array}{rr}
1 & 0 \\
-0.4 & 1
\end{array}\right), C_{11}=\left(\begin{array}{cc}
-0.1 & -0.1 \\
1.2 & 0.4
\end{array}\right), C_{12}=2 \cdot C_{11}
$$

for 210 periods, with initial values of zero for $x_{t-1}$. In each simulation run, independent random numbers for each of the two elements of $\varepsilon_{t}$ are drawn from normal distributions with mean zero and standard deviation $1.0056 \cdot 10^{-5}$, which is the average standard deviation of residuals in our empirical baseline specification. We estimate the time varying impulse response of the second variable with respect to a unit shock in the first element of $\varepsilon_{t}$ with the nonparametric method explained in section 2.1 of the maint text. For each simulation run, we store the eight-period average impulse response. The true values for this measure are 0.2187 in the first and last third of the sample, and 0.4375 in the middle third of the sample. This procedure is repeated 1000 times.

Figure A5: Monte Carlo simulation.
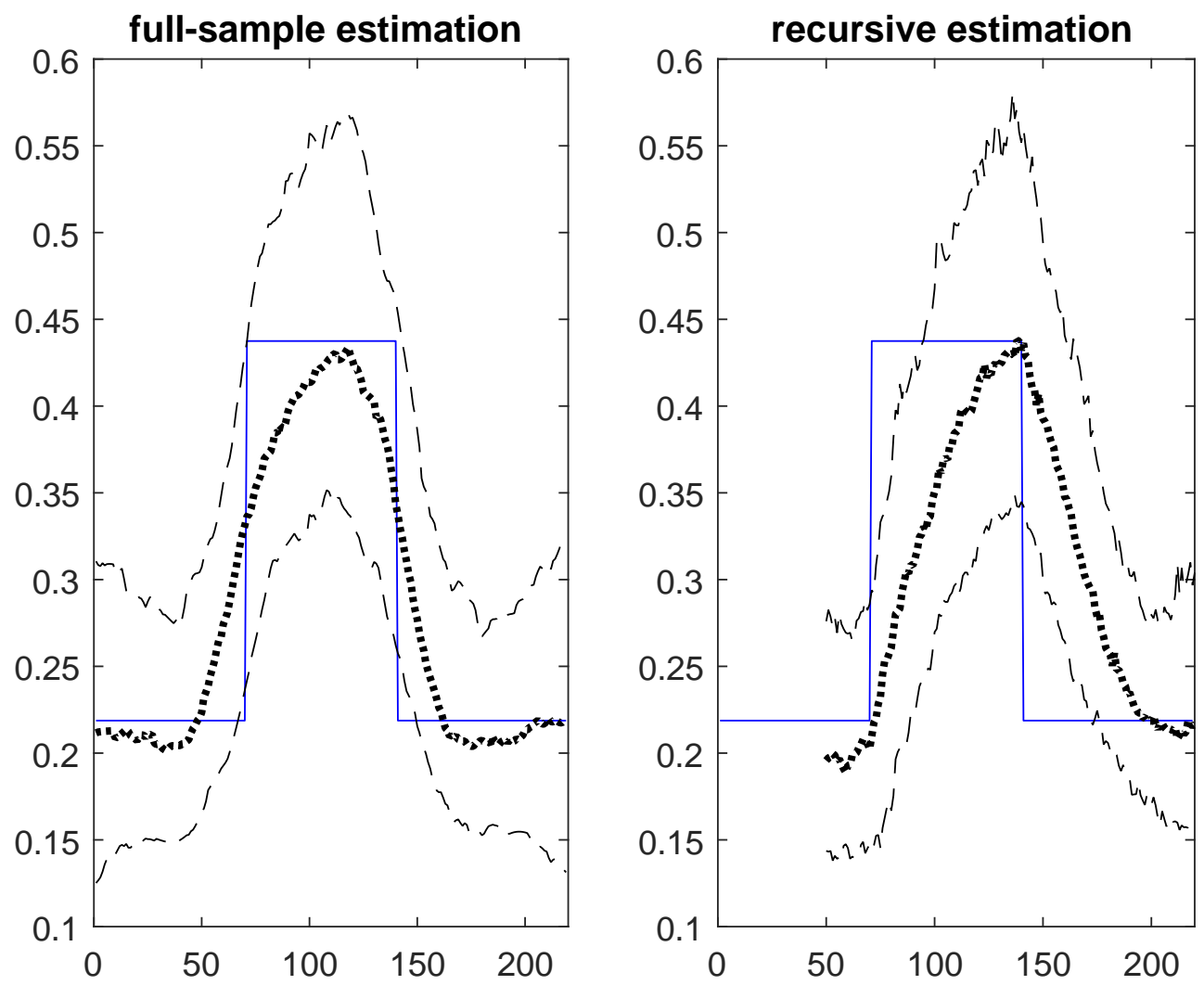

The left panel of Figure A5 shows the results. The increase in the average impulse response is captured well by the estimator. However, it is true that the timing of the 
change is difficult to detect, since the estimated results tend to increase already about 20 periods before the actual change. This is due to the symmetric kernel used, which puts large weights on data surrounding each periods to both sides. Therefore, the right panel of Figure A5 shows the results for recursively estimating the model with data only up to $T^{*}$, where $T^{*}$ is indicated on the horizontal axis. Thus, effectively an asymmetric kernel is used which only sees data to the left of $T^{*}$, where we use the double bandwidth to base the estimation on a comparable number of data points with non-negligible weights. As the right panel of Figure A5 shows, this procedure has the disadvantage that the full amount of the true parameter change is captured later. However, it also has the advantage that the timing of the parameter change can be inferred more precisely, since due to the backward-looking construction of the kernel the estimated response increases only around the time when the true parameter change has taken place. 


\section{A6 Varying the kernel bandwidth}

In our baseline estimation, we follow Giraitis et al. (2014) and set the bandwidth to $h=\sqrt{T}$. Figure A6 shows that our qualitative finding of particular large output responses to government spending shocks during the Great Recession is robust to changes in the bandwidth parameter $h$. In particular, we choose the two smaller bandwidth parameters, $h=T^{0.45}$ and $h=T^{0.4}$. This implies that we increase the weight received by more relatively recent observations in the estimation. $90 \%$ confidence bands from the baseline model are displayed as dashed lines.

Figure A6: Varying the kernel bandwidth.

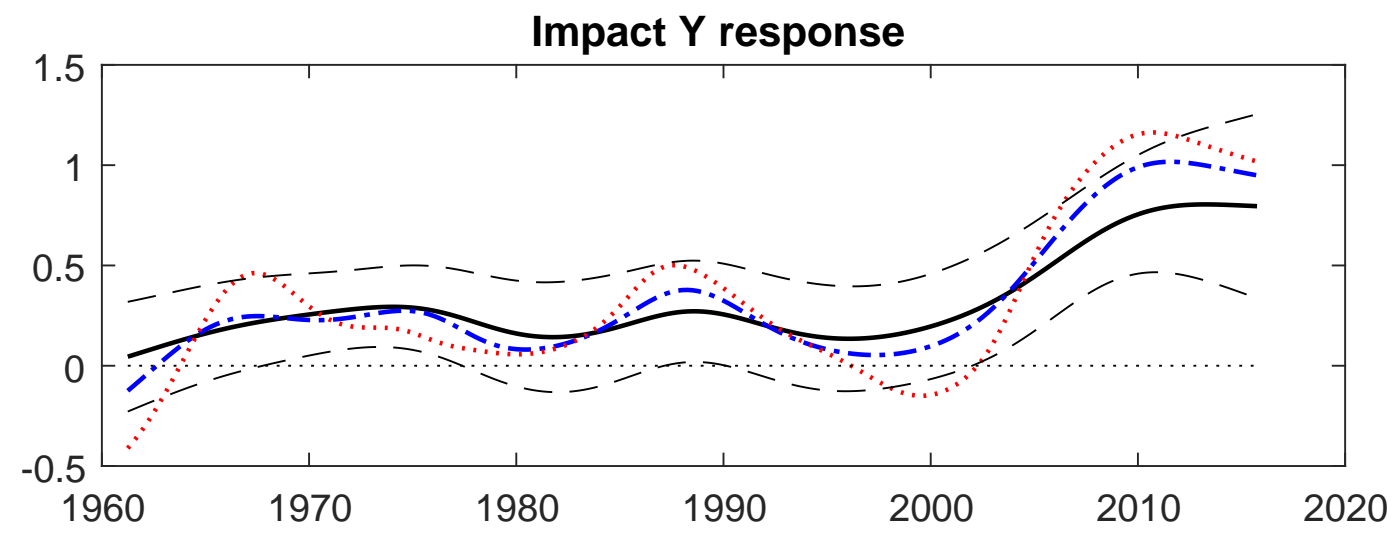

Average $\mathrm{Y}$ response

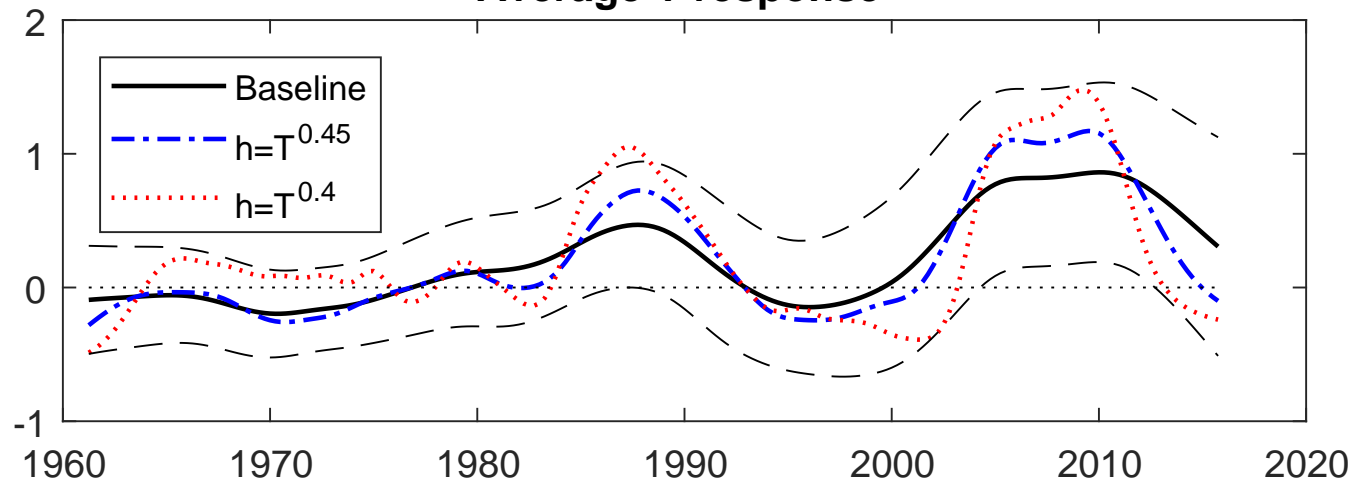




\section{A7 Random walk coefficient model}

We estimate the triangular time-varying VAR model

$$
C_{0 t} x_{t}=C_{1 t} x_{t-1}+e_{t},
$$

where $C_{0 t}$ and $C_{1 t}$ are time-varying coefficient matrices and where $C_{0 t}$ is lower triangular with ones on the main diagonal. The structural disturbance $e_{t}$ is assumed to consist of mutually uncorrelated normally distributed random variables. The $i, j$ - element of $C_{h t}$ (where $\left.h=0,1\right)$ is denoted by $c_{i j h, t}$ and assumed to follow a random walk

$$
c_{i j h, t}=c_{i j h, t-1}+\eta_{i j h, t},
$$

where the innovations $\eta_{i j h, t}$ are normally distributed with mean zero and a constant variance, and the $\eta_{i j h, t}$ are independent of each other and uncorrelated over time.

Since the model is contemporaneously recursive, following Eickmeier et al. (2015) each equation can be separately estimated by maximum likelihood using the Kalman filter formulae in Hamilton (1994). Since the likelihood function is highly nonlinear, we ease the computational complexity by specifying a first order model in three variables consisting of the growth rates of real government spending, real GDP, and the spread of corporate over government bond interest rates, in this order. The Kalman smoothed estimates of the elements of the $C_{h t}$ matrices are then used to calculate impulse responses.

Figure A7: Random walk coefficient model.

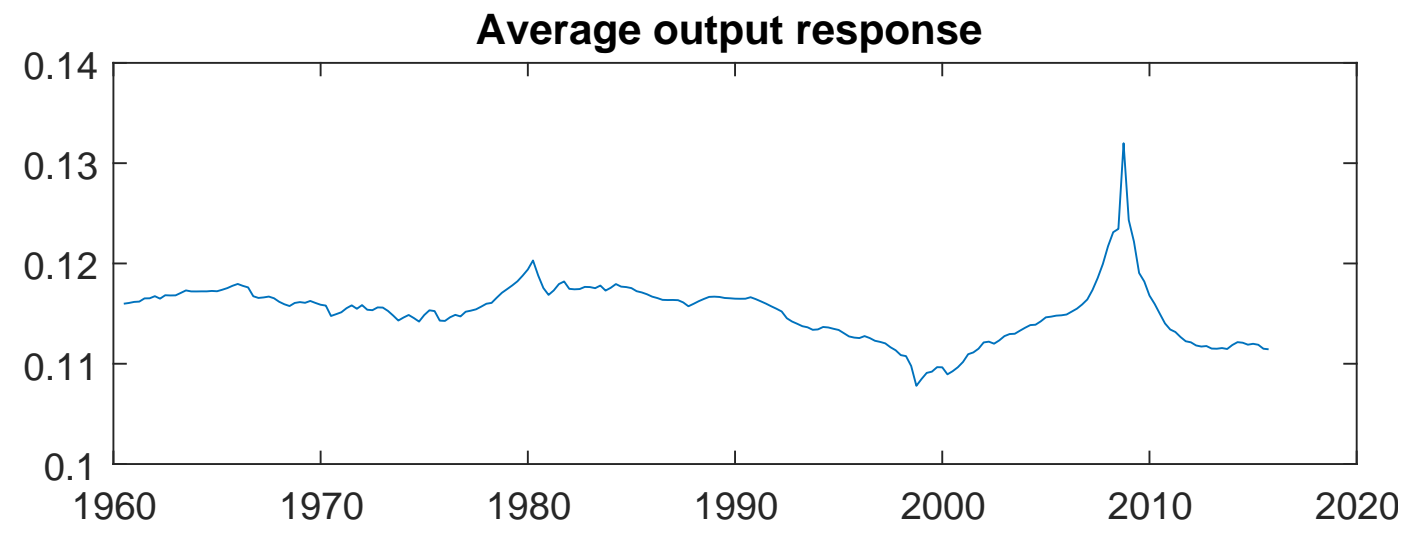

Average spread response

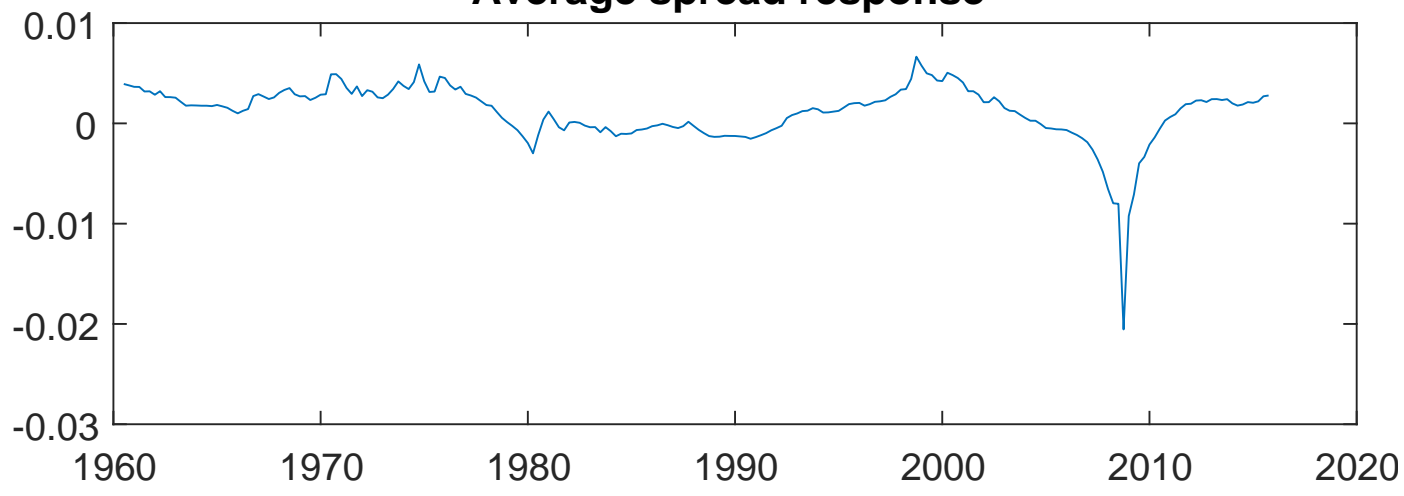


The first panel of Figure A7 shows the eight-quarter average of the time-varying impulse responses of output, whereas the second panel shows the same for the corporate-overgovernment bond spread. As can be seen from the figure, this model generally finds rather limited parameter variation, most of it concentrated around the time of the GR. Quantitatively, the variation is much smaller here compared to what we found by the alternative empirical models shown in the main text. Our interpretation is that the assumption that parameters follow a random walk with innovations drawn from an unchanging normal distribution imposes excessive smoothness on the estimated paramater variation that is not likely to capture very unusual abrupt changes well. However, the interpretation is difficult since the small model that has been chosen to make the maximum likelihood estimation computationally feasible may be too restrictive. The nonparametric approach used in the main text does not have this disadvantage and is therefore more suitable for detecting transmission channels in a large and relatively unrestricted model. In any case, however, the unusualness of the effects of government shocks during the GR period is also clearly visible from the results in Figure A7. 


\section{A8 Long-term interest rate responses}

The following Figure A8 shows the responses of nominal as well as real (ex-post and exante) long-term government bond interest rates. The left panel shows the eight quarter average response of the nominal long-term government bond rate in a modified specification where the government bond rate and the corporate bond rate enter separately (instead of as a spread variable as in the baseline model). The middle and right panels show the eight quarter average response of the corresponding implied ex-post and ex-ante real long-term government bond interest rates.

Figure A8: Long-term interest rate responses.
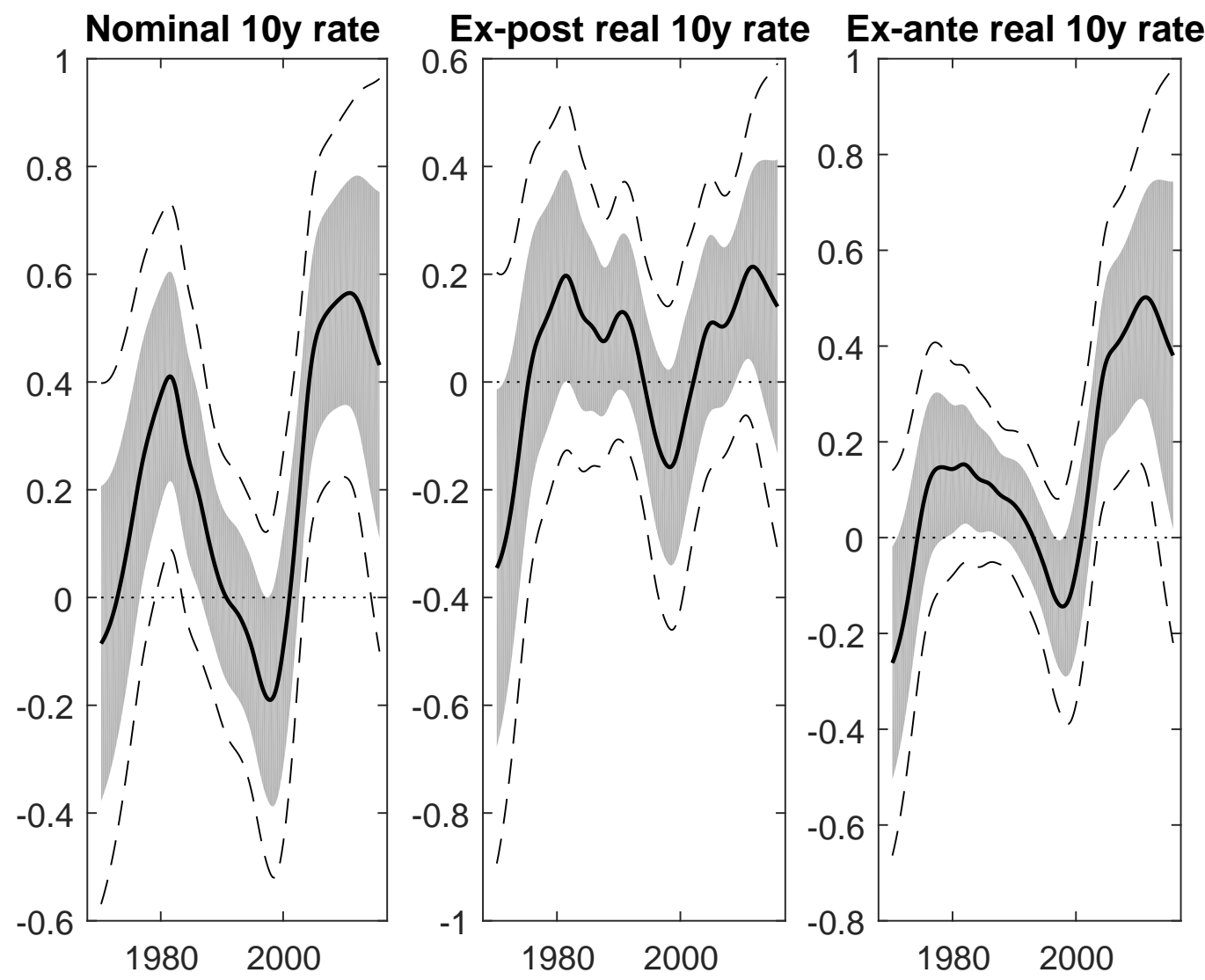

Notes: Solid lines show mean responses. Shaded areas and dashed lines indicate $68 \%$ and $90 \%$ bootstrapped confidence intervals. 


\section{A9 Data}

\begin{tabular}{|c|c|c|}
\hline Variable & Source/Construction & FRED ID \\
\hline (1) Real Gross Domestic Product & FRED & GDPC1 \\
\hline (2) Real Government Spending & FRED & GCEC1 \\
\hline (3) Federal Government Current Receipts & FRED & FGRECPT \\
\hline (4) Federal Government Current Transfers & FRED & W011RC1Q027SBEA \\
\hline (5) Gross Domestic Product & FRED & GDP \\
\hline (6) Government Taxes to GDP & $((3)-(4)) /(5)$ & \\
\hline (7) Federal Government Credit Market Instruments & FRED & FGSDODNS \\
\hline (8) State/Local Governments Credit Market Instruments & FRED & SLGSDODNS \\
\hline (9) Government Debt to GDP & $((7+(8)) /(5)$ & \\
\hline (10) Gross Domestic Product Implicit Price Deflator & FRED & GDPDEF \\
\hline (11) Shadow Federal Funds Rate & Wu and Xia (2016) & \\
\hline (12) Baa Corporate Bond Yield & FRED & BAA \\
\hline (13) Long-term Government Bond Rate & Robert Shillers' homepage & \\
\hline (14) Corporate Spread & $(12)-(13)$ & \\
\hline (15) Consumer Confidence & Michigan Survey of Consumers & \\
\hline (16) Expected Inflation & Survey of Professional Forecasters & \\
\hline (17) Fixed Private Investment & FRED & FPI \\
\hline (18) Fixed Investment Implicit Price Deflator & FRED & A008RD3Q086SBEA \\
\hline (19) Real Fixed Private Investment & $(17) /(18)$ & \\
\hline (20) Personal Consumption Expenditures: Services & FRED & PCESV \\
\hline (21) Personal Consumption Expenditures: Nondurable Goods & FRED & PCND \\
\hline (22) Consumer Price Index & FRED & CPIAUCSL \\
\hline (23) Real Private Consumption & $((20)+(21)) /(22)$ & \\
\hline (24) Civilian Unemployment Rate & FRED & UNRATE \\
\hline (25) Ramey Military News & Valerie Rameys' homepage & \\
\hline (26) Forecast Government Spending & $\begin{array}{l}\text { 1966-2008: Auerbach and Gorodnichenko (2012) } \\
\text { 2009-2015: Survey of Professional Forecasters }\end{array}$ & \\
\hline (27) Real effective Exchange Rate & FRED & RNUSBIS \\
\hline (28) Total government expenditures & FRED & W019RCQ027SBEA \\
\hline
\end{tabular}

\section{A10 References}

Eickmeier, S., W. Lemke, and M. Marcellino (2015), Classical time varying factoraugmented vector auto-regressive models - estimation, forecasting and structural analysis, Journal of the Royal Statistical Society 178, 493-533.

Giraitis, L., G. Kapetanios, and T. Yates (2014), Inference on stochastic time-varying coefficient models, Journal of Econometrics 179, 46-65.

Hamilton, J. D. (1994), Time series analysis, Princeton University Press. 